\title{
Selective Activation of Microglia Facilitates Synaptic Strength
}

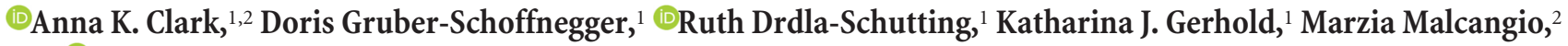 \\ and ${ }^{\circ}$ Jürgen Sandkühler ${ }^{1}$ \\ ${ }^{1}$ Department of Neurophysiology, Center for Brain Research, Medical University of Vienna, A-1090 Vienna, Austria, and ${ }^{2}$ Wolfson Centre for Age Related \\ Diseases, King's College London, London SE1 1UL, United Kingdom
}

\begin{abstract}
Synaptic plasticity is thought to be initiated by neurons only, with the prevailing view assigning glial cells mere specify supportive functions for synaptic transmission and plasticity. We now demonstrate that glial cells can control synaptic strength independent of neuronal activity. Here we show that selective activation of microglia in the rat is sufficient to rapidly facilitate synaptic strength between primary afferent C-fibers and lamina I neurons, the first synaptic relay in the nociceptive pathway. Specifically, the activation of the CX3CR1 receptor by fractalkine induces the release of interleukin- $1 \beta$ from microglia, which modulates NMDA signaling in postsynaptic neurons, leading to the release of an eicosanoid messenger, which ultimately enhances presynaptic neurotransmitter release. In contrast to the conventional view, this form of plasticity does not require enhanced neuronal activity to trigger the events leading to synaptic facilitation. Augmentation of synaptic strength in nociceptive pathways represents a cellular model of pain amplification. The present data thus suggest that, under chronic pain states, CX3CR1-mediated activation of microglia drives the facilitation of excitatory synaptic transmission in the dorsal horn, which contributes to pain hypersensitivity in chronic pain states.
\end{abstract}

Key words: chemokine; chronic pain; fractalkine; microglia; spinal cord; synaptic plasticity

\section{Introduction}

Synaptic plasticity is classically regarded as a hallmark of neurons, requiring both presynaptic and postsynaptic neuronal mechanisms (Bliss and Collingridge, 1993; Malenka and Bear, 2004). Glial cells participate in synaptic transmission; however, while neuron-glia communication is necessary for synaptic plasticity (Gruber-Schoffnegger et al., 2013; Ji et al., 2013; Xanthos and Sandkühler, 2014), it is considered to play a mere supportive role (Ben Achour and Pascual, 2010). Astrocyte modulation of plasticity is evident; the role of microglia is less clear. Microglia release proinflammatory mediators and gliotransmitters that can modulate synaptic transmission (Kawasaki et al., 2008; Gruber-Schoffnegger et al., 2013); however, these factors also originate from other cell types, including astrocytes. Thus, it is currently unknown whether microglia alone are sufficient to modify synaptic strength.

Peripheral damage results in maladaptive augmentation of responses to noxious stimuli at the first nociceptive synapse, between primary afferent $\mathrm{C}$-fibers and dorsal horn neurons. Long-

\footnotetext{
Received May 21, 2014; revised Jan. 13, 2015; accepted Jan. 22, 2015.

Author contributions: A.K.C., D.G.-S., M.M., and J.S. designed research; A.K.C., R.D.-S., and K.J.G. performed research; A.K.C. and R.D.-S. analyzed data; A.K.C., M.M., and J.S. wrote the paper.

This work was funded by a Wellcome Trust Flexible Travel Fellowship (093173/Z/10/Z) to A.K.C. and by a grant from the Austrian Science Fund (FWF) to J.S.

The authors declare no competing financial interests.

This article is freely available online through the J Neurosci Author Open Choice option.

Correspondence should be addressed to Jürgen Sandkühler, Department of Neurophysiology, Center for Brain Research, Medical University of Vienna, Spitalgasse 4, A-1090 Vienna, Austria. E-mail: juergen.sandkuehler@meduniwien.ac.at.

DOI:10.1523/JNEUROSCI.2061-14.2015

Copyright (C) 2015 the authors $\quad 0270-6474 / 15 / 354552-19 \$ 15.00 / 0$
}

term potentiation (LTP) at C-fiber synapses is a cellular model of injury-induced hypersensitivity (Ikeda et al., 2003; Ikeda et al., 2006; Sandkühler, 2009; Zhong et al., 2010; Park et al., 2011) and involves many signal transduction pathways, such as NMDA receptor activation. These same transduction mechanisms are essential for the development of hypersensitivity in models of chronic pain, suggesting that LTP and behavioral hypersensitivity share many common mechanisms (Sandkühler, 2009). Importantly, microglia activity is required for activity-dependent LTP in the dorsal horn and the pronociceptive cytokines interleukin (IL) $-1 \beta$ and tumor necrosis factor (TNF), which can be released by microglia, and can modify synaptic transmission at spinal synapses (Kawasaki et al., 2008; Zhong et al., 2010; GruberSchoffnegger et al., 2013).

Neuron-microglia communication in the spinal cord dorsal horn is vital for the modulation of nociceptive transmission following peripheral damage (Clark and Malcangio, 2012; Ji et al., 2013). A greater understanding of neuron-microglia interactions during chronic pain states has led to the identification of new therapeutic targets, including chemokine receptors such as CX3CR1 (Clark et al., 2011; Clark and Malcangio, 2012). The G-protein-coupled receptor CX3CR1 and its ligand fractalkine (FKN) represent a key signaling pair for neuron-microglia communication in the spinal cord (Clark et al., 2011); CX3CR1 is exclusively expressed by microglia, where it mediates the effect of the neuronal chemokine FKN. Thus, FKN is a unique tool for the specific stimulation of microglia. In chronic pain states, CX3CR1-expressing spinal microglia respond to soluble FKN by intracellular p38 mitogen-activated protein kinase (MAPK) phosphorylation (Clark et al., 2007; Zhuang et al., 2007) and the 
release of proinflammatory mediators (Milligan et al., 2004; Clark et al., 2009), which induce pain hypersensitivity. Microglia released cathepsin S (CatS) is responsible for FKN cleavage from neurons into chemokine domain-containing pronociceptive fragments (Clark and Malcangio, 2012). The therapeutic potential for disruption of FKN/CX3CR1 signaling is widespread; inhibition of CX3CR1 signaling reverses chronic pain behaviors, and CX3CR1-null mice do not develop pain hypersensitivity (Clark and Malcangio, 2014).

Here we investigated whether specific activation of microglia, via the CX3CR1 receptor, is sufficient to induce an amplification of synaptic strength at the first synapse in the nociceptive pathway and the mechanisms by which specific microglial signaling pathways can dynamically modulate nociceptive synaptic strength.

\section{Materials and Methods}

All procedures were in accordance with European Communities Council directives (86/609/EEC) and United Kingdom Home Office regulations.

\section{In vitro electrophysiology}

Spinal cord slice preparation. Transverse spinal cord slices with dorsal roots attached were made from young male Sprague Dawley rats (age range, 25-30 d) as previously described (Ikeda et al., 2003, 2006; GruberSchoffnegger et al., 2013). Briefly, the spinal cord was quickly removed into ice-cold incubation solution consisting of the following (in $\mathrm{mM}$ ): 95 $\mathrm{NaCl}, 1.8 \mathrm{KCl}, 1.2 \mathrm{KH}_{2} \mathrm{PO}_{4}, 0.5 \mathrm{CaCl}_{2}, 7 \mathrm{MgSO}_{4}, 26 \mathrm{NaHCO}_{3}, 15$ glucose, and 50 sucrose, $\mathrm{pH} 7.4$, with measured osmolarity of 310-320 $\mathrm{mOsm} / \mathrm{L}$, oxygenated with $95 \% \mathrm{O}_{2}$ and $5 \% \mathrm{CO}_{2}$. The dura mater and the ventral roots were then removed. Transverse slices $(\sim 500 \mu \mathrm{m}$ thick $)$ from segments L2-L6 with dorsal roots $(10-15 \mathrm{~mm}$ ) attached were cut using a vibrating microslicer (DTK-1000, Dosaka EM). Slices were kept in the incubation solution at $32^{\circ} \mathrm{C}$ for at least $30 \mathrm{~min}$, after which they were stored in the same solution at room temperature $\left(20-24^{\circ} \mathrm{C}\right)$.

Patch-clamp recordings. A single slice was placed in the recording chamber and continuously superfused with oxygenated recording solution at a rate of $3-4 \mathrm{ml} / \mathrm{min}$. The recording solution was identical to the incubation solution except for the following (in $\mathrm{mm}$ ): $127 \mathrm{NaCl}, 2.4$ $\mathrm{CaCl}_{2}, 1.3 \mathrm{MgSO}_{4}$, and 0 sucrose. All recordings were made at $32 \pm 1^{\circ} \mathrm{C}$. Neurons of the dorsal horn were visualized with "Dodt" infrared optics (Dodt and Zieglgänsberger, 1990) using a 40×, 0.80 water-immersion objective on an Olympus BX50WI upright microscope equipped with a video camera. Lamina I neurons were recorded in the whole-cell patchclamp configuration. Only neurons at a distance of $<20 \mu \mathrm{m}$ from the dorsal white/gray matter border were considered as being lamina I neurons and were used for experiments. Patch pipettes (2-4 M $\Omega$ ) from borosilicate glass (Hilgenberg) were pulled on a horizontal puller (P-87, Sutter Instruments). The internal pipette solution consisted of the following (in mM): 120 potassium gluconate, $20 \mathrm{KCl}, 2 \mathrm{MgCl}_{2}, 2 \mathrm{Na}_{2} \mathrm{ATP}$, $0.5 \mathrm{NaGTP}, 20$ HEPES, and 0.5 EGTA, pH adjusted to 7.28 with $\mathrm{KOH}$, with measured osmolarity of $300 \mathrm{mOsm} / \mathrm{L}$. The membrane potential was measured immediately after establishing the whole-cell configuration, and neurons with a membrane potential less negative than $-45 \mathrm{mV}$ were not analyzed further. All recordings were made at a holding potential of $-75 \mathrm{mV}$ using an Axopatch 200B patch-clamp amplifier and the pCLAMP version 10 software package (both Molecular Devices). Signals were low-pass filtered at $2-10 \mathrm{kHz}$, sampled at $10-20 \mathrm{kHz}$, and analyzed off-line using pCLAMP version 10. No correction for the liquid junction potential was made.

Afferent-evoked EPSCs in lamina I neurons were elicited by stimulating dorsal roots electrically via a suction electrode with an isolated current stimulator (A360, World Precision Instruments). After determination of the threshold needed to elicit an EPSC, stimulus intensity was adjusted to $200 \%$ of the threshold value, and test pulses of $0.1 \mathrm{~ms}$ were given at intervals of $30 \mathrm{~s}$ for C-fiber signals, and of $15 \mathrm{~s}$ for $\mathrm{A} \delta$-fiber signals. EPSCs were classified as being C-fiber-evoked when the calculated conduction velocity was $<0.5 \mathrm{~m} / \mathrm{s}$, and as being $\mathrm{A} \delta$-fiber-evoked when the calculated conduction velocity was $>1.5 \mathrm{~m} / \mathrm{s}$. Monosynaptic input was identified by the absence of failures in response to 10 stimuli at
$2 \mathrm{~Hz}$ (for C-fiber input) or at $10 \mathrm{~Hz}$ (A $\delta$-fiber input), and a jitter in response latencies of $<10 \%$ of the response delay. Measurements were made from only one neuron per spinal cord slice in all experiments performed. Series resistance was monitored throughout the experiment. Neurons were discarded if the series resistance changed by $<20 \%$ during the experiment.

Drug application. Drugs were applied to the bath solution at known concentrations. Bicuculline (10 $\mu \mathrm{M}$; Sigma-Aldrich) and strychnine (4 $\mu \mathrm{M}$; Sigma-Aldrich) were included in the recording solution for all experiments. In addition, tetrodotoxin (TTX; $1 \mu \mathrm{M}$; Abcam) was added to the recording solution during some experiments to measure miniature EPSCs (mEPSCs). Rat recombinant FKN (amino acids 25-100; $200 \mathrm{ng} /$ $\mathrm{ml}$; R\&D systems) was applied in the presence and absence of a range of pharmacological agents, as follows: FKN neutralizing antibody (antiFKN; $2 \mu \mathrm{g} / \mathrm{ml}$ for $1 \mathrm{~h}$ preincubation then $1 \mu \mathrm{g} / \mathrm{ml}$ for the duration of the recording; R\&D systems); control goat IgG (IgG; $2 \mu \mathrm{g} / \mathrm{ml}$ for $1 \mathrm{~h}$ preincubation then $1 \mu \mathrm{g} / \mathrm{ml}$ for the duration of the recording; R\&D systems); minocycline ( $100 \mu \mathrm{M}$ for 90 min preincubation then $20 \mu \mathrm{M}$ for duration of the recording; Sigma-Aldrich); IL-1 receptor antagonist (IL-1ra; 40 $\mathrm{ng} / \mathrm{ml}$ for $20 \mathrm{~min}$ preincubation and the duration of the recording; $\mathrm{AbD}$ Serotec); soluble TNF receptor (sTNF R1; $0.5 \mu \mathrm{g} / \mathrm{ml}$ for $20 \mathrm{~min}$ preincubation and the duration of the recording; R\&D Systems); D-amino acid oxidase (D-AAO; $0.2 \mathrm{U} / \mathrm{ml}$ for $1 \mathrm{~h}$ preincubation and the duration of the recording; Sigma-Aldrich); 2-(4-carboxyphenyl)-4,4,5,5-tetramethylimidazoline-1-oxyl-3-oxide (cPTIO; $30 \mu \mathrm{M}$ for 30 min preincubation and the duration of the recording; Tocris Bioscience); $N$-[ [3-(aminomethyl)phenyl]methyl]-ethanimidamide dihydrochloride (1400W; 3 $\mu \mathrm{M}$ for $30 \mathrm{~min}$ preincubation and the duration of the recording; Tocris Bioscience); or arachidonyl trifluoromethyl ketone (AACOCF3; $10 \mu \mathrm{M}$ for 20 min preincubation then for the duration of the recording; Tocris Bioscience). AACOCF3 was initially dissolved in dimethylsulfoxide (DMSO) and then diluted to a final concentration in the recording solution. Thus, control experiments were performed in the presence of DMSO (0.05\% final concentration) under the same experimental conditions as AACOCF3 (20 min preincubation then for the duration of the recording). All other compounds were dissolved directly in the recording solution. Drug-free experiments, in which FKN was applied alone (all shown in Fig. $1 B$ ), were interleaved with experiments using the drug application. In addition, control experiments were performed in the presence of each pharmacological agent, but in the absence of FKN. In other experiments, compounds were included in the pipette solution alone to specifically block postsynaptic signaling mechanisms. The selective NMDA receptor blocker (+)-5-methyl-10,11-dihydro-5Hdibenzo[a,d]cyclohepten-5,10-imine maleate (MK801; $1 \mathrm{~mm}$; Tocris Bioscience) was added to the standard pipette solution (Humeau et al., 2003; Bender et al., 2006; Naka et al., 2013). In further experiments, the $\mathrm{Ca}^{2+}$ chelator bis(2-aminophenoxy)ethane- $N, N, N^{\prime}, N^{\prime}$-tetra-acetic acid (BAPTA; 20 mM; Sigma-Aldrich) was added to the pipette solution consisting of the following (in $\mathrm{mm}$ ): 80 potassium gluconate, $20 \mathrm{KCl}, 2$ $\mathrm{MgCl}_{2}, 2 \mathrm{Na}_{2} \mathrm{ATP}, 0.5 \mathrm{NaGTP}, 20$ HEPES, and 0.5 EGTA, pH 7.28 with $\mathrm{KOH}$, and measured osmolarity of $300 \mathrm{mOsm} / \mathrm{L}$. In both cases, recording was initiated $15 \mathrm{~min}$ after whole-cell patch was achieved to allow full diffusion of MK801/BAPTA within the postsynaptic neuron.

Retrograde labeling of projection neurons. Young (age range, 21-24 d) male Sprague Dawley rats were deeply anesthetized with a mixture of ketamine and xylazine $(9: 1 ; 3.4 \mathrm{ml} / \mathrm{kg})$ and placed in a stereotaxic apparatus. A hole was drilled through the skull for insertion of a $500 \mathrm{nl} \mathrm{Ham}$ ilton syringe needle $(0.51 \mathrm{~mm}$ outer diameter). Two injections of $20 \mathrm{nl}$ (40 nl total volume) of $2.5 \% 1,1^{\prime}$-dioctadecyl-3,3,3',3'-tetramethylindocarbocyanine perchlorate (DiI), separated by $1 \mathrm{~min}$, were made into the right side of the periaqueductal gray (PAG) according to the atlas of Paxinos and Watson (1982). After recovery from anesthesia, the animals fed and drank normally. Three to four days following injection, lumbosacral segments of the spinal cord were excised and transverse spinal cord slices were prepared as described above. The brain of each injected rat was removed, and the injection site was verified by microscopy. Following confirmation of an accurate PAG injection, projection neurons were identified in the slice by DiI labeling. 

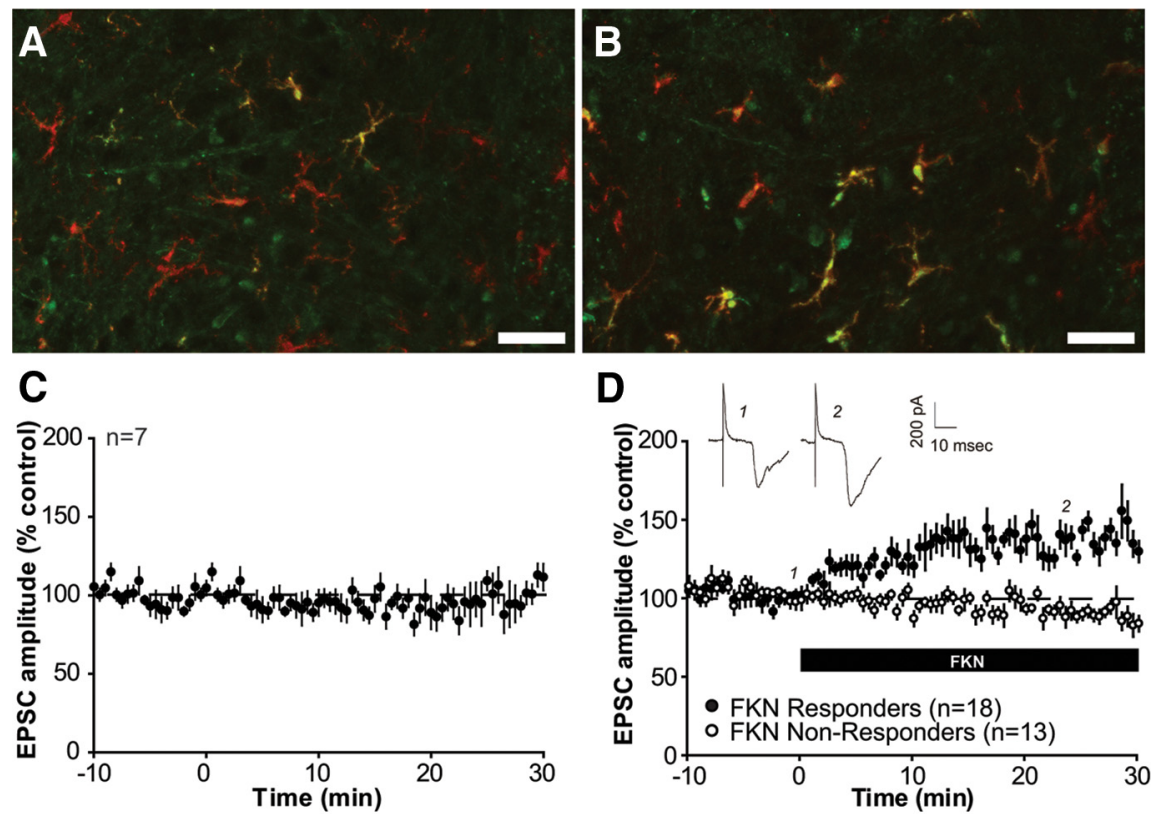

E

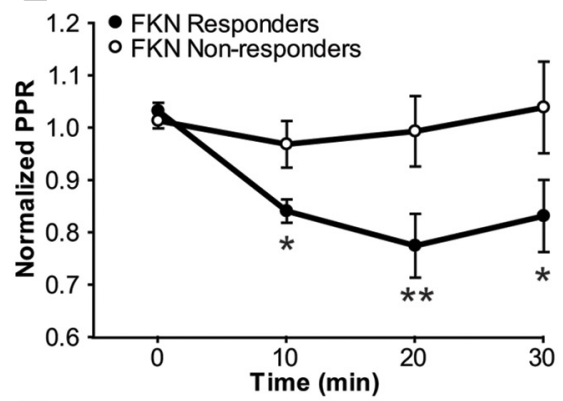

G
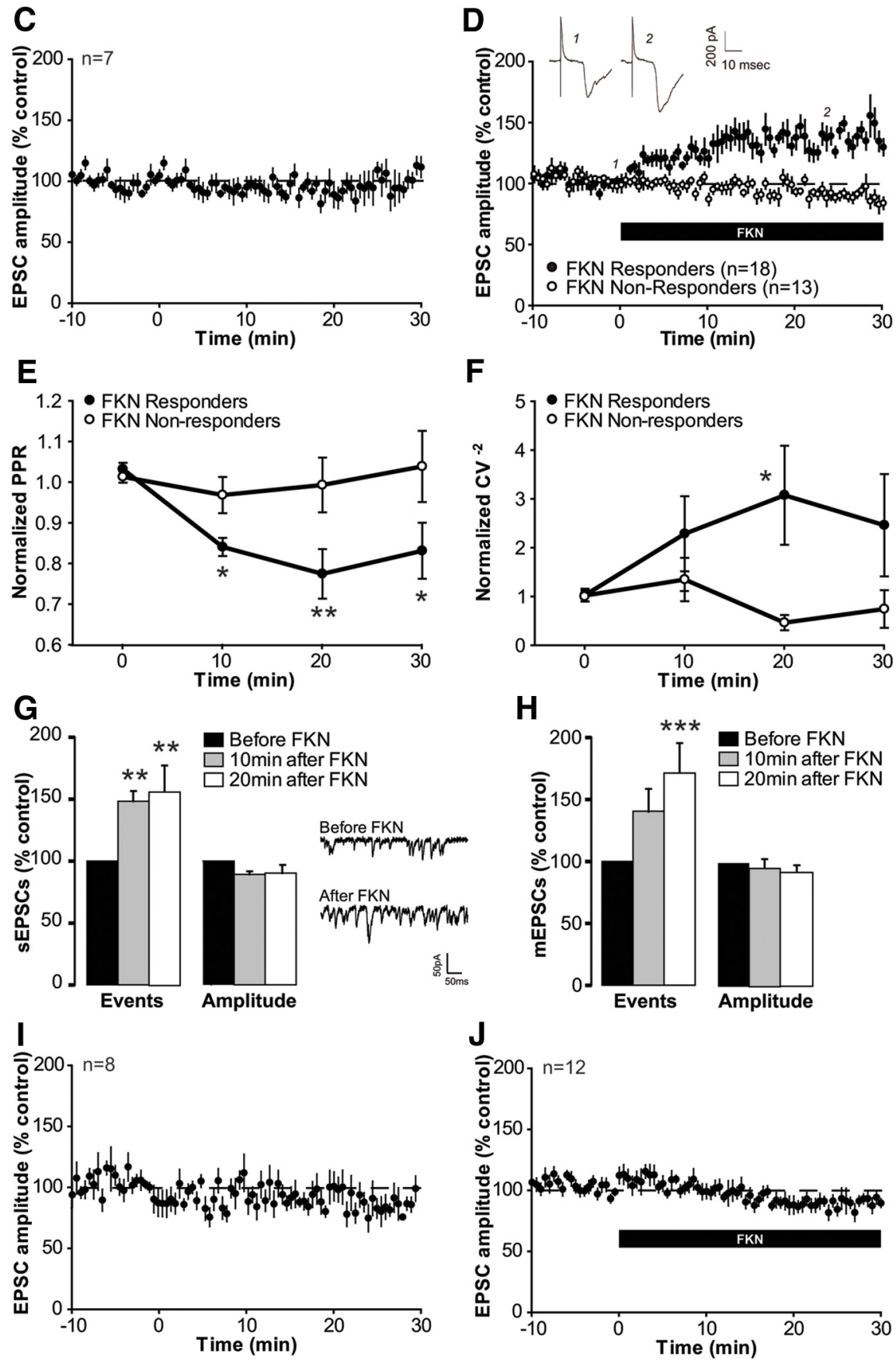

$\mathbf{F}$

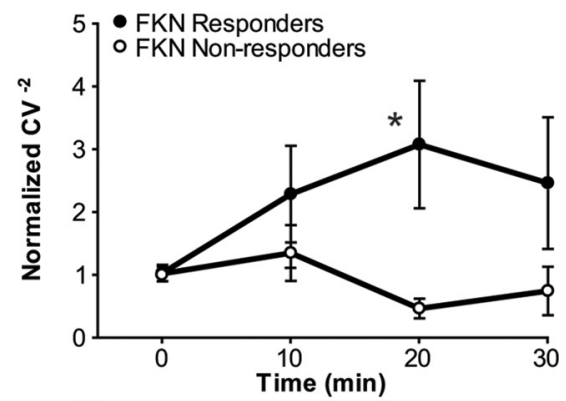

H

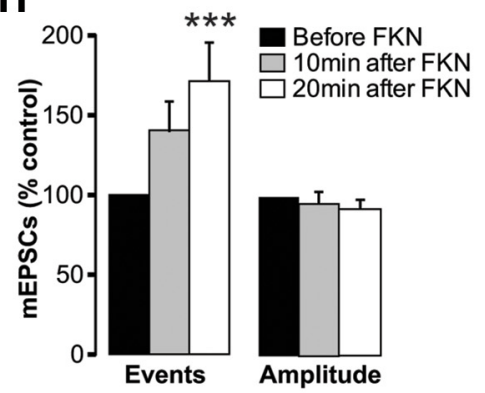

J

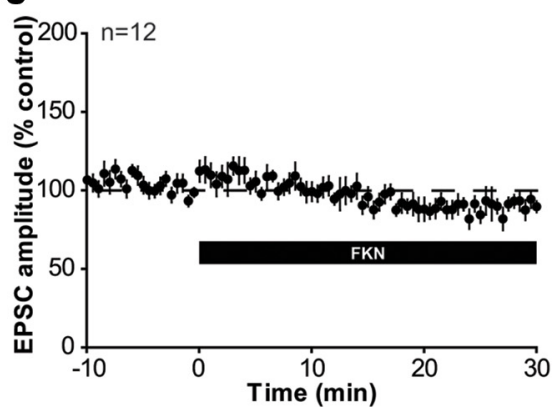

Figure 1. FKN induces rapid enhancement of synaptic transmission. $\boldsymbol{A}, \boldsymbol{B}, \mathrm{lba}-1$ (red) and p-p38 MAPK (green; colocalization with Iba-1, yellow) immunoreactivity in the dorsal horn of control $(\boldsymbol{A})$ and FKN $(\boldsymbol{B})$ spinal cord slices. Scale bar, $50 \mu \mathrm{m}$. $\boldsymbol{C}$, In seven neurons tested, C-fiber-evoked EPSC amplitude stays constant over a recording period of $40 \mathrm{~min}$ ( $p>0.05$, one-way RM ANOVA). D, FKN (200 ng/ml for $30 \mathrm{~min}$, black bar) induced a significant facilitation of C-fiber-evoked EPSC amplitude in 18 of 31 neurons tested [134 $\pm 6 \%$ at 30 min, $p<0.001$, one-way RM ANOVA; $p<0.01$ compared with control neurons (C), Fisher's exact test]. Filled circles represent neurons showing statistically significant facilitation ( $p<0.05$, one-way RM ANOVA; FKN Responders); open cycles, neurons showing no change after FKN application ( $p>0.05$, one-way RM ANOVA; FKN Nonresponders). Insets show
Data analysis. Synaptic strength was quantified by measuring the amplitude of monosynaptic EPSCs. Amplitudes were calculated by subtracting the baseline from the peak amplitude. The mean amplitude of six EPSCs evoked by test stimuli served as a control period. The effects of FKN were quantified as a percentage change in EPSC amplitude, comparing the amplitudes of the last six EPSCs to the control period. The synaptic strength of each individual neuron was assessed statistically at several time points (pre-FKN vs 10, 20, and 30 min after FKN application) using a one-way ANOVA. Neurons that exhibited a statistically significant $(p<0.05)$ change of synaptic strength (compared with their own baseline) were classified as FKN responders. Neurons that did not exhibit a statistically significant change in synaptic strength were classified as FKN nonresponders. Two pulses were given with an interstimulus interval of $200 \mathrm{~ms}$. The pairedpulse ratio (PPR) was determined by dividing the amplitude of the second EPSC by the amplitude of the first EPSC and averaging over 3 min epochs of six EPSCs. The squared coefficient of variation $\left[\mathrm{CV}^{-2}\left(\mathrm{CV}^{-2}=\right.\right.$ mean $^{2} /$ variance)] was calculated for $3 \mathrm{~min}$ epochs of six EPSCs and normalized to the control period. Spontaneous EPSCs (sEPSCs) and mEPSCs were counted and analyzed off-line using MiniAnalysis software (Synaptosoft). sEPSCs and mEPSCs were analyzed only in neurons with a noise level of $<3.5 \mathrm{pA}$. Each sEPSC/mEPSC event was visually accepted or rejected based upon the rise and decay times after an automatic screening by the software.

\section{In vivo electrophysiology}

Field potential recordings. Experiments were performed in adult male Sprague Dawley rats. Isoflurane in two-thirds $\mathrm{N}_{2} \mathrm{O}$ and one-third $\mathrm{O}_{2}$ was used to induce [ 4 volume percent (vol\%) inspiratory] and maintain (1.5 vol\% expiratory) anesthesia. Concentrations of gases were measured and monitored with a capnograph (Capnomac Ultima, Datex-Ohmeda). The surgical level of anesthesia was verified by stable arterial blood pressure and by the absence of a

individual EPSC traces recorded from a FKN responding neuron at the indicated time points. $\boldsymbol{E}, \boldsymbol{F}$, Facilitation of C-fiber-evoked EPSC by FKN is associated with a decrease in the PPR $(\boldsymbol{E})$ and an increase in the $\mathrm{CV}^{-2}$ value $(\boldsymbol{F})$ compared with pretreatment values $\left({ }^{*} p<0.05,{ }^{* *} p<0.01\right.$, one-way RM ANOVA). $\mathbf{G}, \boldsymbol{H}$, FKN application is associated with an increase in the number of $\operatorname{sEPSCs}[\mathbf{G} ; 148 \pm 10 \%$ at $10 \mathrm{~min}, 157 \pm 21 \%$ at 20 min after FKN $(n=11)]$ and $\mathrm{mEPSCs}[\boldsymbol{H} ; 139 \pm 18 \%$ at $10 \mathrm{~min}, 173 \pm$ $22 \%$ at 20 min after FKN $(n=10)]$ compared with pretreatment values ${ }^{* *} p<0.01,{ }^{* * *} p<0.001$, one-way RM ANOVA). Insets show representative traces of $\mathrm{EEPSC}$. $I$, In seven neurons tested, $A \delta$-fiber-evoked EPSC amplitude stays constant over a recording period of $40 \mathrm{~min}(p>0.05$, oneway RM ANOVA). J, FKN ( $200 \mathrm{ng} / \mathrm{ml}$ for $30 \mathrm{~min}$, black bar) did not modify $A \delta$-fiber-evoked EPSC amplitude in 12 neurons tested [ $89 \pm 5 \%$ at $30 \mathrm{~min}, p>0.05$, one-way RM ANOVA; $p>0.05$ compared with control neurons (I), Fisher's exact test]. 
reflex during pinching the interdigital area of the forepaw. Animals were intubated with a 14 ga cannula for mechanical ventilation with a respirator (Servo Ventilator 900C, Siemens). The right femoral artery and vein were then cannulated with a polyethylene catheter to continuously monitor blood pressure and to allow infusions of intravenous solutions. During anesthesia, animals continuously received an intravenous solution (58\% Ringer's solution, 30\% HAES, $8 \%$ glucose, and $4 \%$ sodium bicarbonate, $2 \mathrm{ml} / \mathrm{h}$ ) for stabilization of blood pressure (mean, 130-160 $\mathrm{mmHg}$ ), and base excess (mean, $-1.5 \pm 0.8 \mathrm{mmol} / \mathrm{L}$ ). The arterial catheter was flushed every $30 \mathrm{~min}$ with a heparinized sodium solution (2.5 $\mathrm{IU} / \mathrm{ml}$ ) to prevent blood agglutination. Arterial blood gas analyses were performed every $30 \mathrm{~min}$. Colorectal temperature was kept at $\sim 37^{\circ} \mathrm{C}$ with a feedback-controlled heating blanket (Panlab). The left sciatic nerve was dissected free for bipolar stimulation with a silver hook electrode. The electrode was then isolated from surrounding muscles with a plastic film. A laminectomy was performed to expose lumbar segments four and five (L4-L5). Two metal clamps were used for fixation of the animal vertebral column in a stereotactic frame. An agarose pool was formed around the exposed spinal segments. The exposed part of the sciatic nerve was covered with warm paraffin oil. Muscle relaxation was achieved by intravenous injection of $2 \mu \mathrm{g} / \mathrm{kg} / \mathrm{h}$ pancuronium bromide. Electrophysiological recordings were performed as previously described (Drdla et al., 2009; Drdla-Schutting et al., 2012; Gruber-Schoffnegger et al., 2013). Briefly, C-fiber-evoked field potentials were recorded with glass electrodes (impedance, 2-3 M $\Omega$ ) from lamina I and II of the spinal cord dorsal horn in response to the stimulation of sciatic nerve fibers. The pipette solution consisted of the following (in $\mathrm{mm}$ ): $135 \mathrm{NaCl}, 5.4 \mathrm{KCl}, 1.8 \mathrm{CaCl}_{2}, 10$ HEPES, $1 \mathrm{MgCl}_{2}$, and $0.2 \%$ rhodamine B (Sigma-Aldrich). Electrodes were driven by a microstepping motor. Recordings were made with an ISODAM amplifier (ISO-STIM 01D, npi electronic) using a bandwidth filter of $0.1-1000 \mathrm{~Hz}$. Signals were monitored on a digital oscilloscope and digitized by an analog-to-digital converter. Afferent input from the hindpaw was identified by mechanical stimulation of the foot while acoustically evaluating the evoked responses with an audio monitor. Test stimuli were delivered to the sciatic nerve and consisted of single pulses of $0.5 \mathrm{~ms}$ at an intensity of $25 \mathrm{~V}$ given every $5 \mathrm{~min}$ using an electrical stimulator. Rat recombinant FKN (amino acids 25-100; $200 \mathrm{ng} / \mathrm{ml} ; \mathrm{R} \& \mathrm{D}$ systems), anti-CX3CR1 (rabbit anti-CX3CR1; $60 \mu \mathrm{g} / \mathrm{ml}$; Torrey Pines Institute for Molecular Studies), and control IgG (rabbit IgG; $60 \mu \mathrm{g} / \mathrm{ml}$ ) were dissolved in artificial CSF to obtain the desired concentrations and were applied directly onto the spinal cord dorsum. At the end of each electrophysiological experiment, pressure was applied to the electrode (300 mbar for $1 \mathrm{~min}$ ) for marking the recording site with rhodamine B.

Data analysis. The area under the curve of C-fiber-evoked field potentials was determined off-line using Clampfit version 10. The mean area under the curve of at least six consecutive field potentials before FKN application served as a control period. Responses were normalized for each rat.

\section{Release of $I L-1 \beta$ from dorsal horn slices}

Dorsal horn slice preparation. Horizontal dorsal horn slices with dorsal roots attached were obtained, as previously described (Clark et al., 2006, 2009), from the lumbar spinal cord of adult male Sprague Dawley rats. Briefly, the lumbosacral spinal cord was excised and longitudinally hemisected, producing a horizontal slice with L4 and L5 dorsal roots attached. One slice was obtained from each rat, mounted in the central compartment of a three compartment chamber and continuously superfused $(1 \mathrm{ml} / \mathrm{min})$ with oxygenated $\left(95 \% \mathrm{O}_{2}\right.$ plus $\left.5 \% \mathrm{CO}_{2}\right) \mathrm{Krebs}$ solution, as follows (in mM): $118 \mathrm{NaCl}, 4.7 \mathrm{KCl}, 1.2 \mathrm{MgSO}_{4}, 1.2 \mathrm{KH}_{2} \mathrm{PO}_{4}, 25$ $\mathrm{NaHCO}_{3}, 2.5 \mathrm{CaCl}_{2}$, and 11 glucose, containing $0.1 \%$ bovine serum albumin and $20 \mu \mathrm{g} / \mathrm{ml}$ bacitracin to minimize protein degradation. The dorsal roots were placed in the lateral compartments and immersed in mineral oil to avoid dehydration.

Collection of superfusate samples. Before, during, and after chemical stimulation, fractions of $8 \mathrm{ml}$ of the superfusates were collected from the central compartment in ice-chilled glass tubes to minimize IL- $1 \beta$ loss. FKN was diluted in Krebs' solution and superfused $(200 \mathrm{ng} / \mathrm{ml}$ for 16 $\mathrm{min})$ through naive dorsal horn slices. Three $8 \mathrm{ml}$ fractions were collected before stimulation ( $0-24 \mathrm{~min})$ to measure basal levels of IL-1 $\beta$.
These values were then pooled and expressed as "basal." Two fractions were collected during FKN superfusion (24-40 $\mathrm{min}$ ), and three fractions were collected after FKN superfusion to assess recovery to basal levels of IL- $1 \beta$ [recovery fraction (R) 1, 40-48 min; R2, 48-56 min; R3, 56-64 min].

$I L-1 \beta$ quantification and data analysis. To quantify IL- $1 \beta$ content in superfusates, $8 \mathrm{ml}$ samples were desalted and concentrated using an Ultrafree-15 $10 \mathrm{~K}$ centrifugal device (Millipore). Retentates were lyophilized, reconstituted in $150 \mu \mathrm{l}$ of sample buffer (R\&D Systems) and assayed for IL- $1 \beta$ content by ELISA. Ninety-six-well colorimetric "sandwich" ELISA plates (IL-1 $\beta /$ IL-1F2 Quantikine ELISA Kit, R\&D Systems) were used to determine IL- $1 \beta$ content. Rat recombinant IL- $1 \beta$ standards (50 $\mu \mathrm{l}$ of a $2000-15.6 \mathrm{pg} / \mathrm{ml}$ solution) and $50 \mu \mathrm{l}$ of unknown samples were run in duplicate following the instructions of the manufacturer. The optical density of each well was determined at a wavelength of $450 \mathrm{~nm}$. Samples were considered to be IL- $1 \beta$ positive when the signal was higher than background signal (modified Krebs' solution) and was within the range of the standard curve. Data are expressed as the percentage of IL- $1 \beta$ content in the basal fractions.

\section{Immunohistochemistry}

At the completion of in vivo experiments, animals were under anesthesia, transcardially perfused with a $0.9 \%$ saline solution followed by $4 \%$ paraformaldehyde in $0.1 \mathrm{~m}$ phosphate buffer containing $1.5 \%$ picric acid. The lumbar spinal cord was excised and post-fixed for $4 \mathrm{~h}$ in the perfusion fixative. Spinal cord slices were fixed overnight in $4 \%$ paraformaldehyde in $0.1 \mathrm{M}$ phosphate buffer containing $1.5 \%$ picric acid. All tissues were then cryoprotected in $20 \%$ sucrose in $0.1 \mathrm{~m}$ phosphate buffer $(72 \mathrm{~h}$ at $4^{\circ} \mathrm{C}$ ) and were frozen in O.C.T. embedding compound (VWR). Transverse sections $(20 \mu \mathrm{m})$ were cut with a cryostat and thaw mounted onto glass slides. For staining of the microglial cell population, phosphorylated p38 ( p-p38) MAPK (rabbit anti-p-p38 MAPK; 1:100; Cell Signaling Technology) was visualized with extra avidin-FITC (1:500; Sigma) following signal amplification with $\mathrm{ABC}$ (Vector Laboratories) and biotinyl tyramide (NEN Life Science Products) as previously described (Clark et al., 2006, 2010, 2012). Sections were then incubated with a primary antibody for Iba-1 (ionized calcium binding adapter molecule-1) followed by a secondary antibody solution (goat anti-rabbit IgG-conjugated Alexa Fluor 546, 1:1000; Invitrogen). Slides were coverslipped with Vectashield mounting medium (Vector Laboratories) and visualized under a Zeiss LSM710 confocal microscope. Quantitative assessment of immunostaining in spinal cord sections was performed by counting the number of positive profiles within a fixed area of the dorsal horn (Clark et al., 2006, 2010, 2012). A box measuring $10^{4} \mu \mathrm{m}^{2}$ was placed onto areas of the lateral, central, and medial dorsal horn, and the number of profiles that were positive for each marker were counted within this area. These measurement protocols were performed on three spinal sections from each animal per slice by an assessor blinded to treatment.

\section{Statistical analysis}

All values are given as the mean \pm SEM. For the analysis of electrophysiological and release data, one-way repeated-measures (RM) ANOVA followed by Tukey's post hoc test was used. A Fisher's exact test was used to analyze the response incidence between groups for electrophysiological data. For immunohistochemical data, one-way ANOVA followed by Tukey's post hoc test or Student's $t$ test was used as appropriate. A p level of $<0.05$ was set as the level of statistical significance.

\section{Results}

\section{FKN induces facilitation of synaptic strength at the first synapse in the nociceptive pathway}

Is the activation of microglia CX3CR1 sufficient to induce amplification of synaptic strength? We used the chemokine FKN to specifically stimulate spinal microglia via the CX3CR1 receptor. We first examined whether FKN was able to modulate microglia reactivity in spinal cord slices using immunohistochemistry for p-p38 MAPK, a marker of rapid microglia reactivity (Svensson et al., 2003; Clark et al., 2006). As expected, the number of Iba-1- 
A
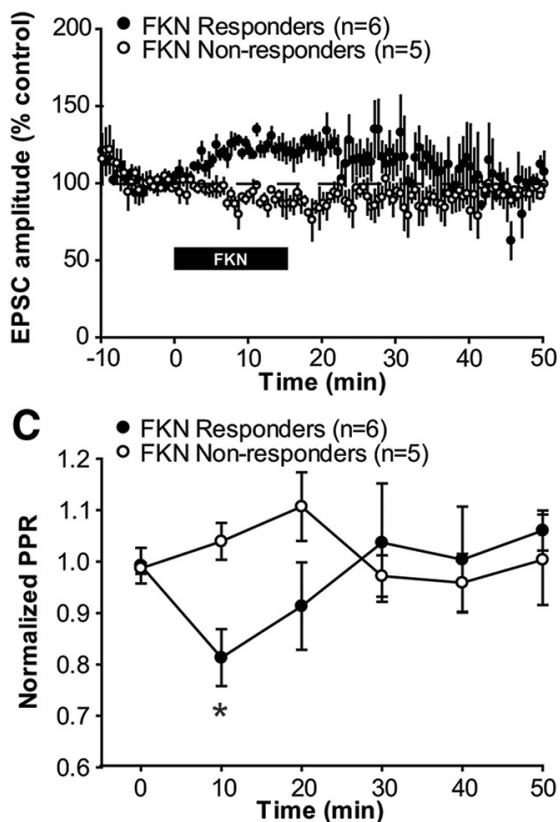

E
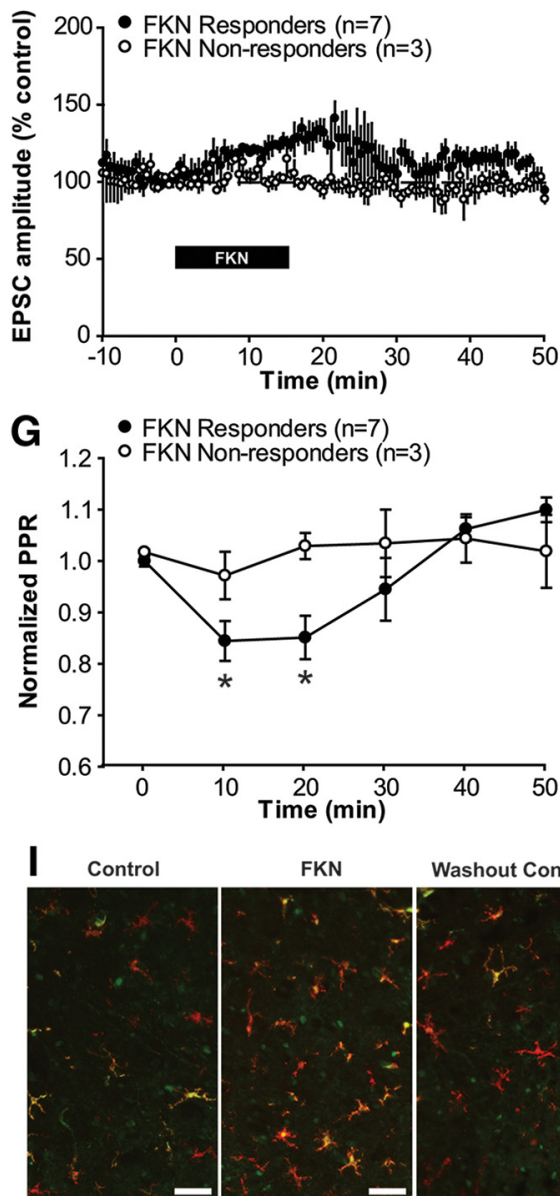

FKN

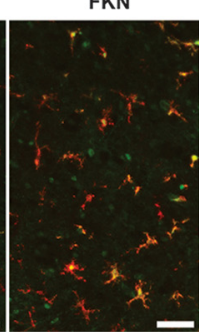

Washout Control
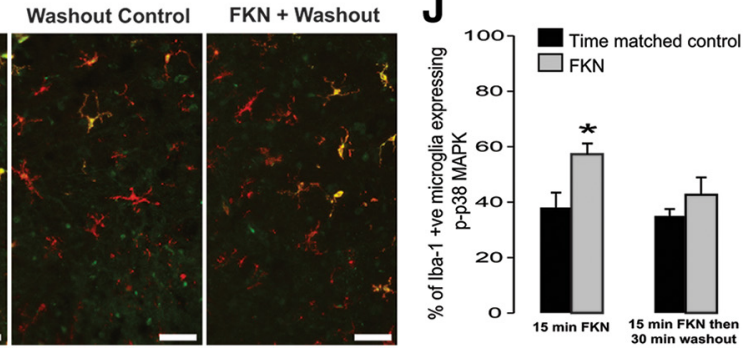

Figure 2. FKN-induced synaptic facilitation is transient in nature. $\boldsymbol{A}$, FKN $(200 \mathrm{ng} / \mathrm{ml}$ for $15 \mathrm{~min}$, black bar) induced a significant facilitation of C-fiber-evoked EPSC in 6 of 11 neurons tested, which returned to pretreatment values following washout ( $125 \pm 4 \%$ at $15 \mathrm{~min}, 126 \pm 12 \%$ at $30 \mathrm{~min}, p<0.001 ; 107 \pm 9 \%$ at $50 \mathrm{~min}, p>0.05$; one-way RM ANOVA). Filled circles represent neurons showing facilitation; open cycles represent neurons showing no change after FKN application. $\boldsymbol{B}-\boldsymbol{D}$, FKN significantly modified sEPSCS $(\boldsymbol{B})$, PPR $(\boldsymbol{C})$, and $C V^{-2}(\boldsymbol{D})$ during application, with all measures returning to pretreatment values following washout. ${ }^{*} p<0.05$, one-way RM ANOVA. $\boldsymbol{E}$, In identified projection neurons, FKN (200 ng/ml for $15 \mathrm{~min}$, black bar) induced a significant facilitation of C-fiber-evoked EPSCs in 7 of 10 neurons tested, which returned to pretreatment values following washout (124 \pm positive microglial cells in spinal cord slices remained unchanged following a 30 min application of FKN, compared with time-matched control slices. However, following FKN application, the number of microglia exhibiting immunoreactivity for p-p38 MAPK was enhanced compared with control slices (Fig. 1A,B). In control slices, $34 \pm 3 \%$ of Iba-1-positive microglial cells exhibited p-p38 immunoreactivity (Fig. $1 A$ ). This was significantly enhanced ( $p<0.01$, Student's $t$ test) following FKN application, with $63 \pm 6 \%$ of microglia showing p-p38 immunoreactivity (Fig. 1B).

We then examined whether FKN was sufficient to modulate synaptic transmission between primary afferent C-fibers and spinal lamina I neurons in vitro. Under control conditions, C-fiber-evoked EPSC amplitudes stayed stable at $106 \pm$ $5 \%$ of baseline over a recording period of 40 min (Fig. 1C). Bath application of FKN increased synaptic strength at C-fiber synapses in 18 of 31 neurons to $134 \pm 6 \%$ of baseline (Fig. 1D). FKN-induced enhancement of synaptic strength is accompanied by a decrease in the PPR (Fig. $1 E$ ) and an increase in the $\mathrm{CV}^{-2}$ (Fig. $1 F$ ), suggesting a potential presynaptic mechanism of expression.

We concomitantly examined changes in sEPSC in the presence of FKN. FKN significantly increased the number of sEPSCs recorded from lamina I neurons to $157 \pm 21 \%$ of baseline (Fig. $1 G ; n=11$; $p<0.01$, one-way RM ANOVA), while the amplitudes of the recorded sEPSCs remained unchanged at $90 \pm 6 \%$ of baseline (Fig. $1 G ; n=11 ; p>0.05$, one-way RM ANOVA). Under control conditions, the number of sEPSCs remained stable throughout the $40 \mathrm{~min}$ recording period, reaching $88 \pm 6 \%$ and $95 \pm 4 \%$ of baseline $(n=7 ; p>0.05$, one-way $\mathrm{RM}$ ANOVA), respectively, at the time points

$4 \%$ at $15 \mathrm{~min}, 131 \pm 9 \%$ at $20 \mathrm{~min}, p<0.001 ; 107 \pm 3 \%$ at $50 \mathrm{~min}, p>0.05$; one-way RM ANOVA). Filled circles represent neurons showing facilitation; open circles represent neurons showing no change after FKN application. $\boldsymbol{F}-\boldsymbol{H}$, FKNmodified sEPSCS (F), PPR (G), and $\mathrm{CV}^{-2}(\boldsymbol{H})$ during application, with all measures returning to pretreatment values following washout. ${ }^{*} p<0.05,{ }^{* *} p<0.01$, one-way RM ANOVA. II lba-1 (red) and p-p38 MAPK (green; colocalization with Iba-1, yellow) immunoreactivity in the dorsal horn of spinal cord slices following 15 min incubation with FKN, 15 min FKN followed by a 30 min washout period, and time-matched control slices for each condition. Scale bars, $50 \mu \mathrm{m}$. J, Quantification of the percentage of Iba-1-positive microglial cells expressing immunoreactivity for $\mathrm{p}-\mathrm{p} 38 \mathrm{MAPK}$ in the dorsal horn of spinal cord slices. 
A
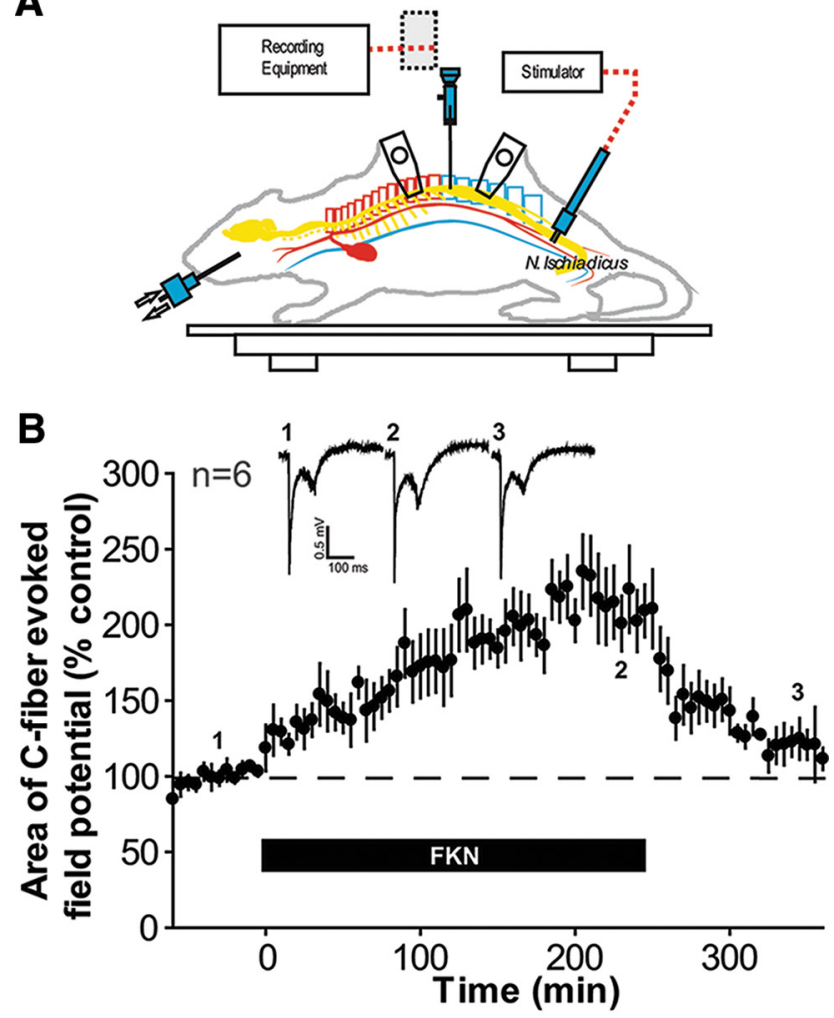

C
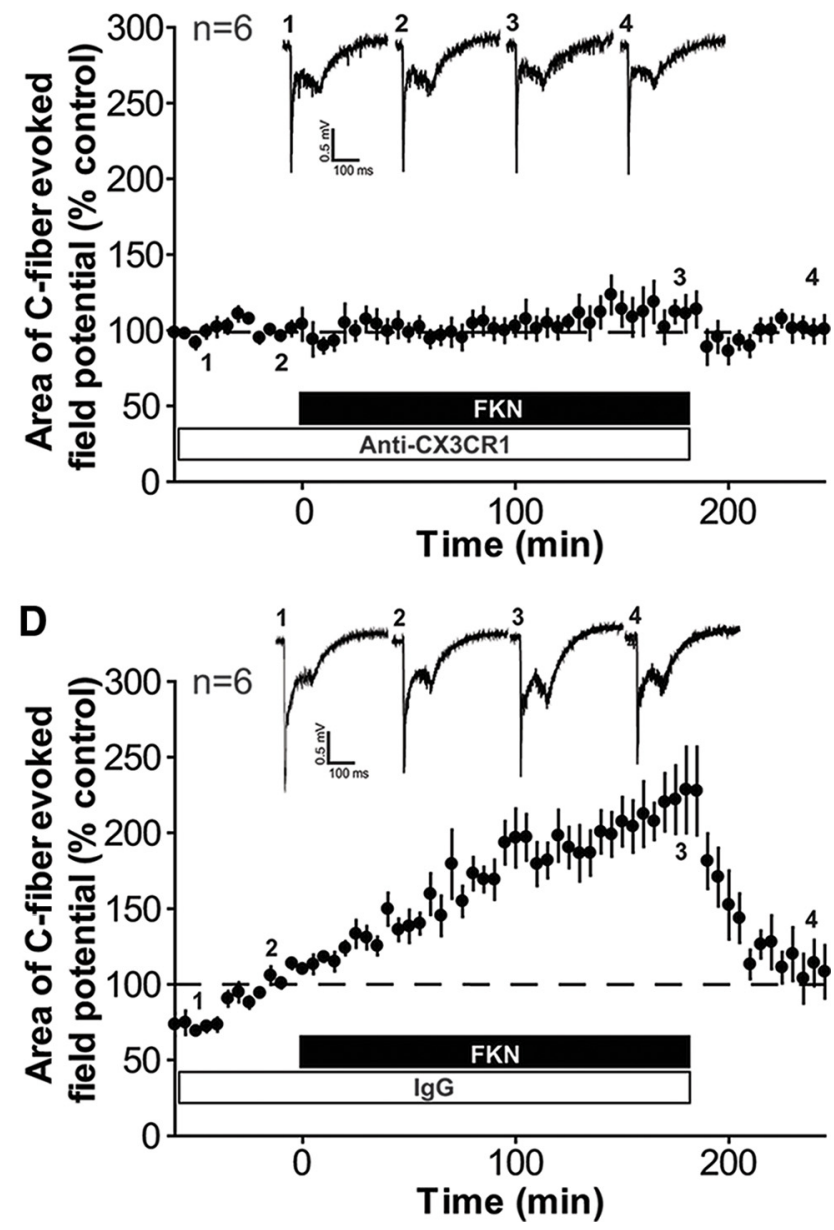

equivalent to 10 and 20 min after FKN application. sEPSC amplitudes also remained stable under control conditions, reaching $96 \pm 3 \%$ and $96 \pm 2 \%$ of baseline $(n=7 ; p>0.05$, one-way RM ANOVA) at the time points equivalent to 10 and $20 \mathrm{~min}$ after FKN application. We then recorded mEPSCs in the presence of TTX in separate neurons. FKN significantly increased the number of mEPSCs to $173 \pm 22 \%$ of baseline, while the amplitude of mEPSCs remained stable at $92 \pm 4 \%$ of baseline (Fig. $1 H$ ).

We then examined whether FKN was sufficient to modulate synaptic transmission between primary afferent $\mathrm{A} \delta$-fibers and spinal lamina I neurons. Under control conditions, A $\delta$-fiberevoked EPSC amplitudes stayed stable at $88 \pm 8 \%$ of baseline over a recording period of $40 \mathrm{~min}$ (Fig. 1I). In 12 neurons tested, bath application of FKN did not significantly modify $\mathrm{A} \delta$-fiberevoked EPSC amplitudes compared with control cells, reaching $89 \pm 7 \%$ of baseline (Fig. $1 \mathrm{~J}$ ). These data suggest that FKNinduced changes in synaptic strength are input specific, occurring between primary afferent $\mathrm{C}$-fibers and lamina I neurons, but not between primary afferent $\mathrm{A} \delta$-fibers and lamina I neurons.

We next investigated the duration of FKN-induced changes to synaptic strength to determine whether this effect was LTP or a short-term facilitation. FKN induced a significant increase in synaptic strength at C-fiber synapses in 6 of 11 neurons to $125 \pm$ $4 \%$ of baseline at $15 \mathrm{~min}$ following FKN application (Fig. 2A). Following FKN washout, synaptic strength remained significantly enhanced at $30 \mathrm{~min}$ (126 $\pm 12 \%$ of baseline; $15 \mathrm{~min}$ after FKN washout), but returned to baseline values thereafter (108 \pm $10 \%$ and $98 \pm 2 \%$ of baseline, respectively, at 40 and $50 \mathrm{~min}$ ). Indeed, FKN induced significant changes in sEPSCs (Fig. 2B), PPR (Fig. 2C), and $\mathrm{CV}^{-2}$ (Fig. 2D) during application, with all parameters returning to control values following FKN washout. We further examined whether projection neurons also responded to FKN in a similar manner to unidentified neurons. Following injection of the retrograde tracer DiI into the PAG projection neurons can be identified by DiI labeling in the slice. Indeed, FKN induced a significant increase in synaptic strength at C-fiber synapses in 7 of 10 identified projection neurons to $124 \pm$ $5 \%$ of baseline at 15 min following FKN application (Fig. 2E). Following FKN washout, synaptic strength remained significantly enhanced at $20 \mathrm{~min}(131 \pm 9 \%$ of baseline, $5 \mathrm{~min}$ after FKN washout), but returned to baseline values thereafter (109 \pm $16 \%, 113 \pm 5 \%$, and $107 \pm 3 \%$ of baseline, respectively, at 30, 40 and $50 \mathrm{~min}$ ). FKN-induced changes in sEPSCs (Fig. $2 F$ ), PPR (Fig. 2G), and $\mathrm{CV}^{-2}$ (Fig. $2 \mathrm{H}$ ) during application, with all parameters returning to control values following $\mathrm{FKN}$ washout. We further investigated whether the return of synaptic strength to baseline values following the washout of FKN was paralleled by observable changes in microglia reactivity. Similarly to a $30 \mathrm{~min}$ application of FKN (Fig. $1 A, B$ ), incubation of spinal cord slices with $\mathrm{FKN}$ for 15 min induced a significant increase in the per-

Figure 3. FKN-induced synaptic facilitation in vivo is $\mathrm{XX3CR} 1$ dependent. The area of the (-fiber-evoked field potential (percentage of control) is plotted against time (in minutes). $\boldsymbol{A}$, Schematic drawing of the recording setup for in vivo experiments. B, Application of FKN (200 $\mathrm{ng} / \mathrm{ml}$ for $240 \mathrm{~min}$, black bar) to the spinal cord induced a facilitation of (-fiber-evoked field potentials in all rats tested, which returned to pretreatment values following washout (223 \pm $28 \%$ at $240 \mathrm{~min}, p>0.001 ; 111 \pm 7 \%$ at $370 \mathrm{~min}, p<0.05$; one-way RM ANOVA). C, FKN-induced facilitation was completely prevented by spinal application of a CX3CR1 neutralizing antibody (rabbit anti-CX3CR1; $60 \mu \mathrm{g} / \mathrm{ml} ; 1 \mathrm{~h}$ before FKN application, open bar; $110 \pm$ $12 \%$ at $180 \mathrm{~min}, p>0.05$, one-way RM ANOVA). D, FKN-induced facilitation was evident following spinal application of control lgG (rabbit lgG; $60 \mu \mathrm{g} / \mathrm{ml} ; 1 \mathrm{~h}$ before FKN application, open bar; $217 \pm 19 \%$ at 180 min, $p>0.05$, one-way RM ANOVA). 
A
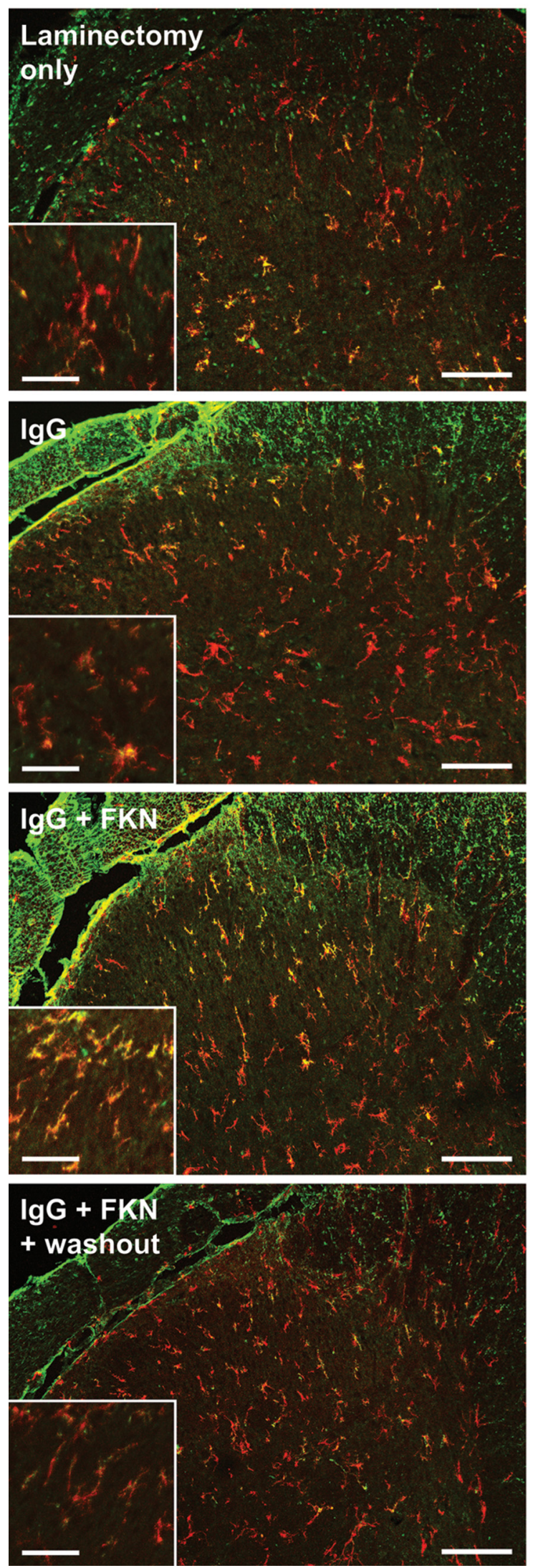

B

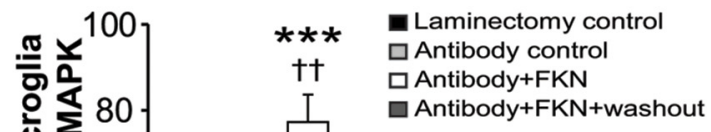

$\square$ Antibody+FKN+washout

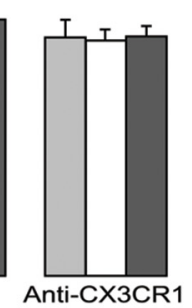

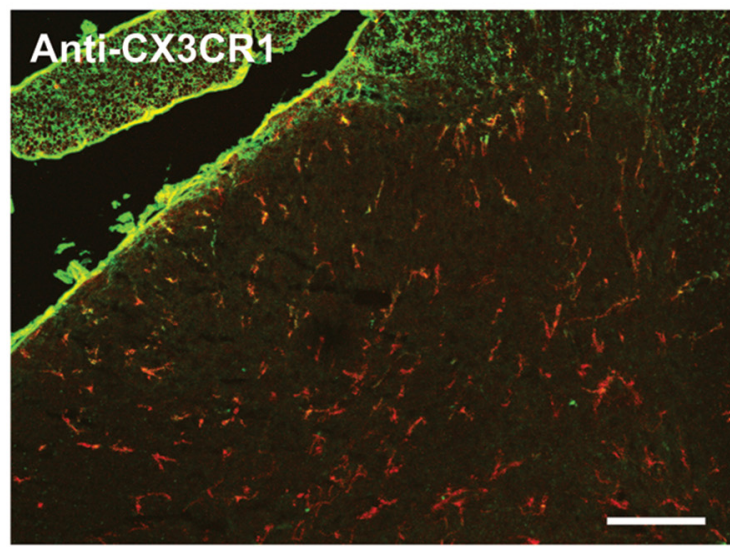

\section{Anti-CX3CR1}

$+\mathrm{FKN}$ ?
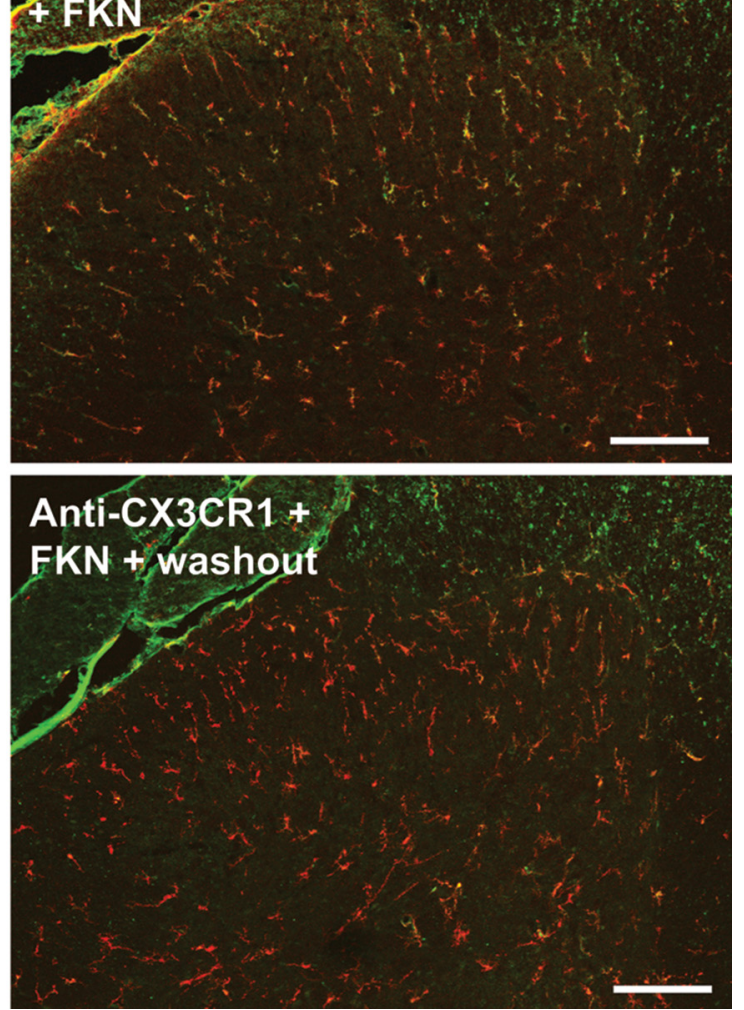

Figure 4. FKN induced microglia reactivity in vivo. $A$, Iba-1 (red) and p-p38 MAPK (green; colocalization with Iba-1, yellow) immunoreactivity in the dorsal horn of the spinal cord following in vivo experiments. Spinal cords were excised under the following conditions: laminectomy only, IgG alone, IgG plus FKN for $180 \mathrm{~min}$, IgG plus FKN plus washout for 60 min, anti-CX3CR1 alone, anti-CX3CR1 plus FKN for $180 \mathrm{~min}$, and anti-CX3CR1 plus FKN plus washout. Scale bars: low-magnification panels, $200 \mu \mathrm{m}$; higher-magnification panels, $100 \mu \mathrm{m}$. $n=4$ rats/group. $\boldsymbol{B}$, Quantification of the percentage of Iba-1-positive microglial cells expressing immunoreactivity for p-p38 MAPK in the dorsal horn of the spinal cord. 
A

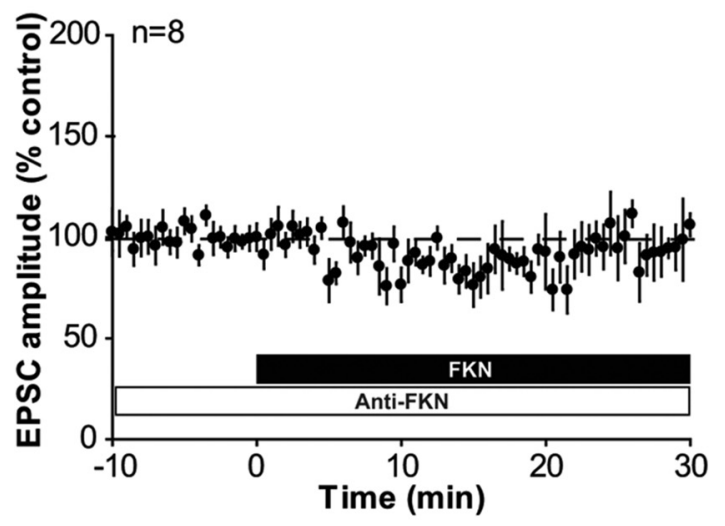

C

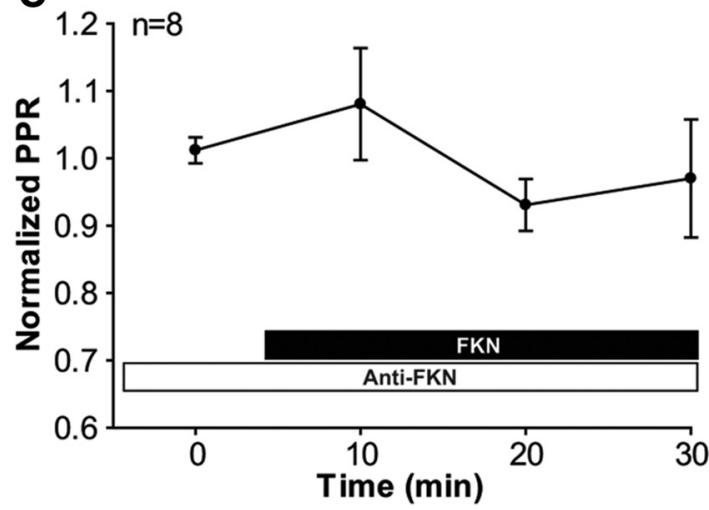

E

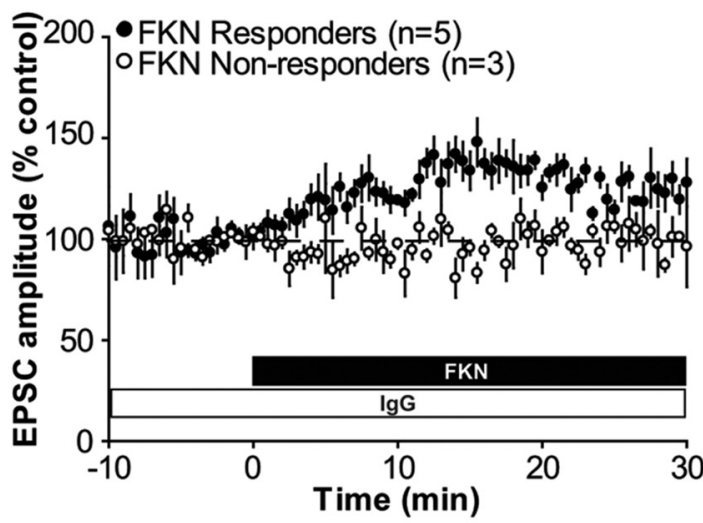

G

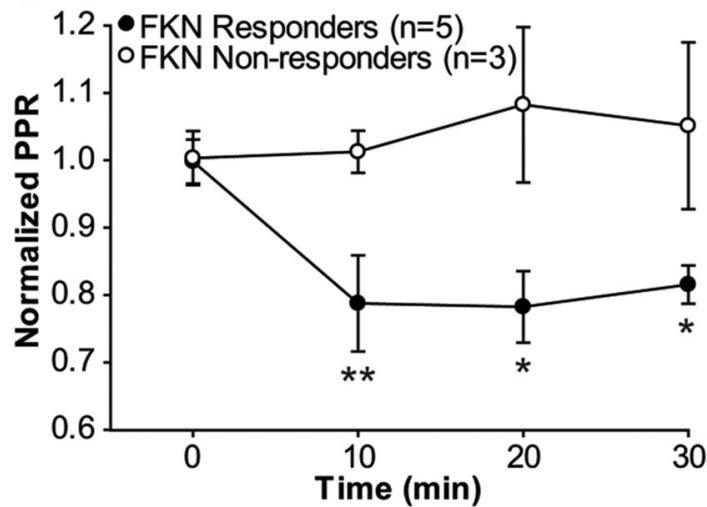

B

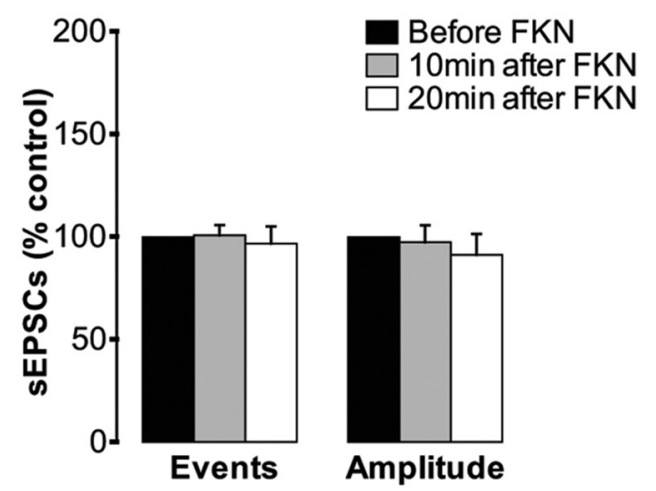

D

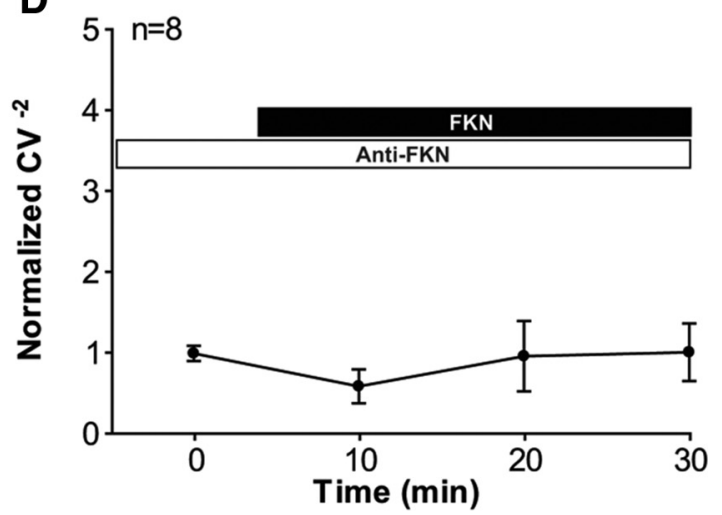

F

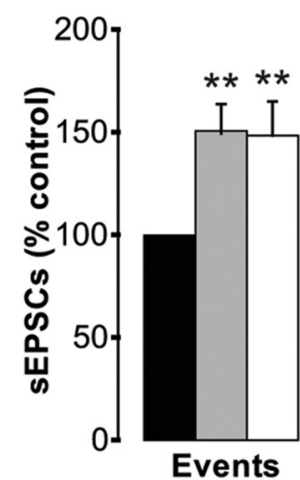

Before FKN

$\square 10$ min after FKN

$\square 20 \mathrm{~min}$ after FKN

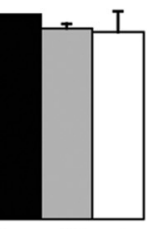

Amplitude

H

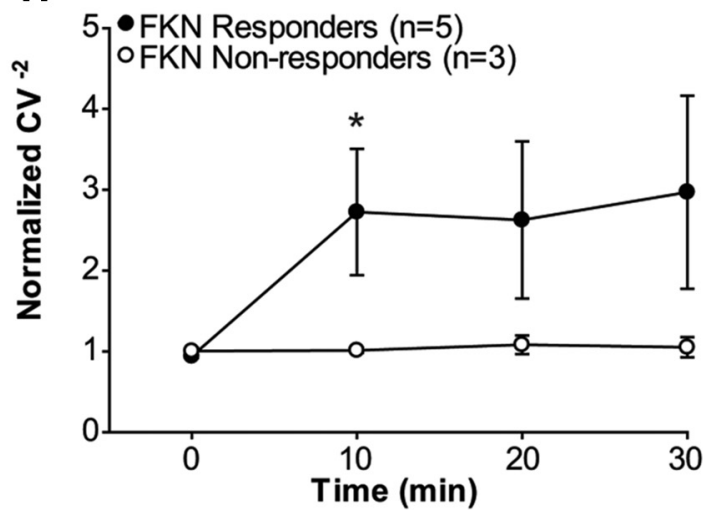

Figure 5. The effects of FKN are mediated by microglial CX3CR1. A-D, In the presence of anti-FKN (goat anti-FKN; $2 \mu \mathrm{g} / \mathrm{ml}$ for $1 \mathrm{~h}$ preincubation then $1 \mu \mathrm{g} / \mathrm{ml}$ for duration of the recording, open bar), FKN (black bar) does not modify C-fiber-evoked EPSCS $(\boldsymbol{A})$, SEPSCS (B), PPR $(\boldsymbol{C}), \operatorname{or~CV}^{-2}(\boldsymbol{D})$ in any neuron tested. $p>0.05$, one-way RM ANOVA. $\boldsymbol{E}$, In the presence of control lgG (goat IgG; 2 $\mu \mathrm{g} / \mathrm{ml}$ for $1 \mathrm{~h}$ preincubation then $1 \mu \mathrm{g} / \mathrm{ml}$ for the duration of the recording, open bar), FKN (black bar) induced a significant facilitation of C-fiber-evoked EPSC (Figure legend continues.) 
A

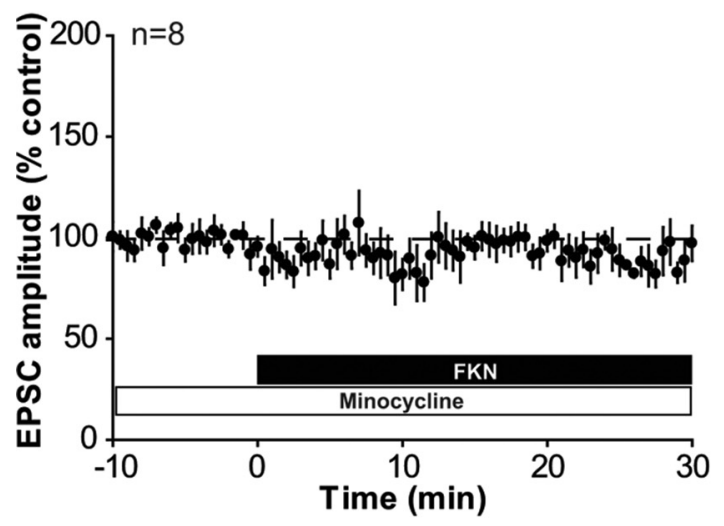

C

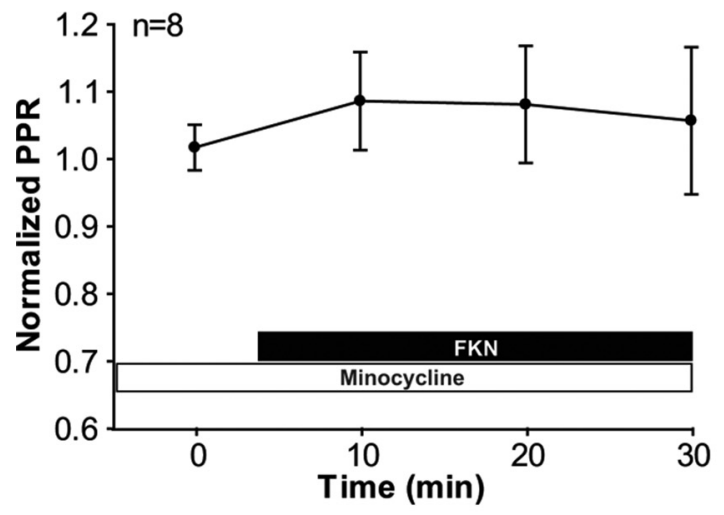

E

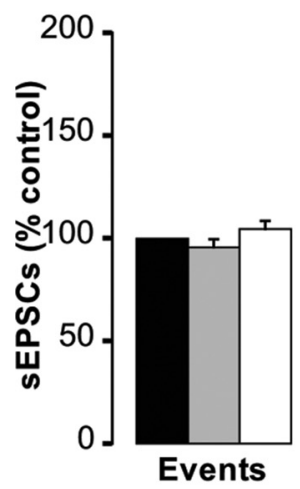

B

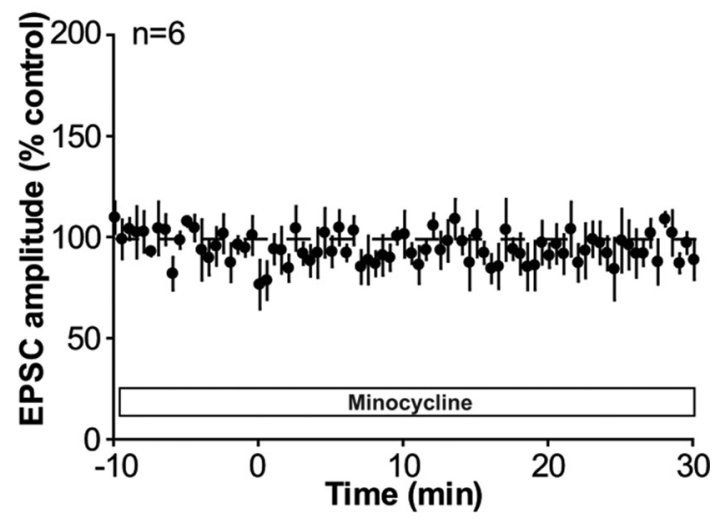

D

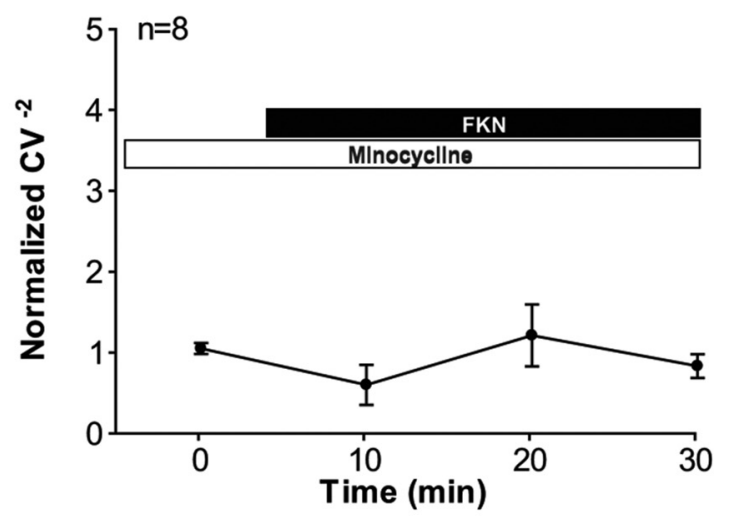


A
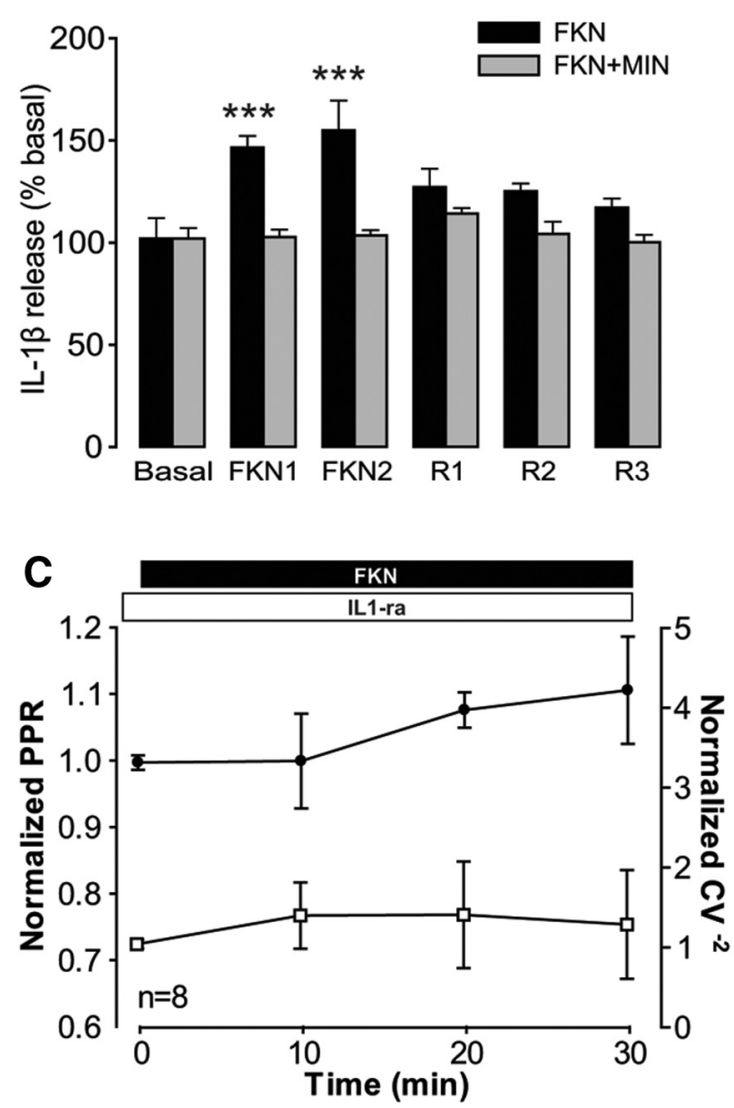

E

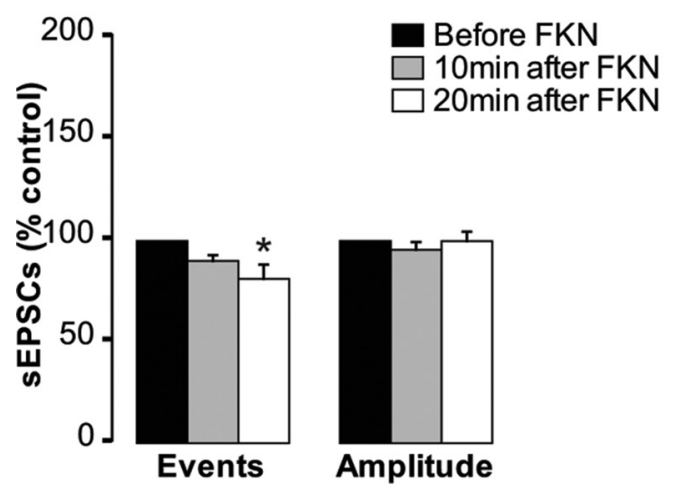

B

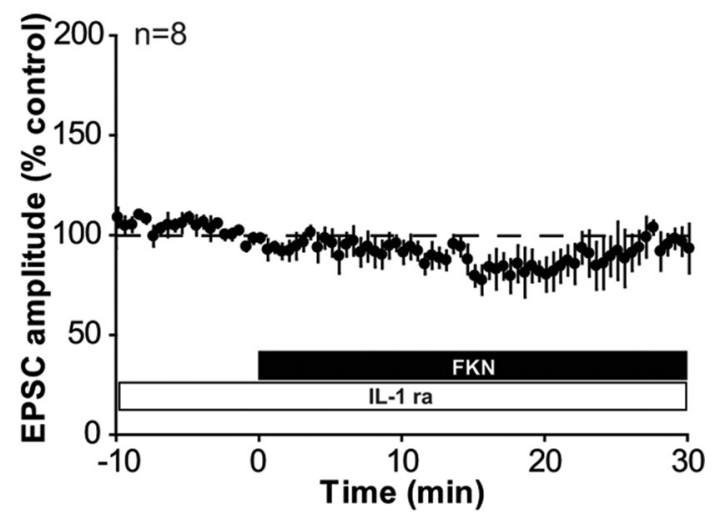

D

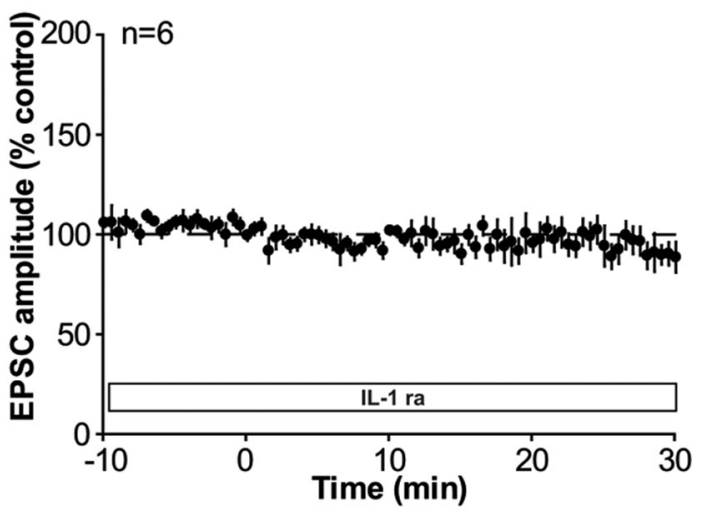

Figure 7. Release of IL- $1 \beta$ is critical for FKN-induced facilitation. $A$, Superfusion of FKN ( $200 \mathrm{ng} / \mathrm{ml}$ for $16 \mathrm{~min})$ resulted in a significant release of IL- $1 \beta$ from the dorsal horn ( $n=13$ slices; black columns; ${ }^{* *} p<0.001$ compared with basal values, one-way ANOVA). Minocycline (MIN) incubated before and during FKN superfusion ( $100 \mu \mathrm{m} ; 24$ min in total) inhibits FKN-evoked IL-1 $\beta$ release ( $n=12$ slices; gray columns; $p>0.05$ compared with basal values, one-way ANOVA). Basal release: FKN $=21.48 \pm 1.69 \mathrm{pg} / 8 \mathrm{ml}$ fraction. FKN + MIN $=23.06 \pm 0.79 \mathrm{pg} / 8 \mathrm{ml}$ fraction. $\boldsymbol{B}-\boldsymbol{E}$, In the presence of IL-1ra ( $40 \mathrm{ng} / \mathrm{ml}$ for 20 min preincubation and the duration of the recording, open bar), FKN-induced facilitation of C-fiber-evoked EPSCs (B) and changes in PPR (C; black circles, left hand axis) and $\mathrm{CV}^{-2}(\boldsymbol{C}$; white squares, right hand axis) were prevented in all neurons tested $(\boldsymbol{B}, \boldsymbol{C} ; p>0.05$, one-way RM ANOVA), while a decrease in the number of sEPSCs occurred $(\boldsymbol{E} ; 81 \pm 7 \%$ at 20 min after FKN $[n=8]$; ${ }^{*} p<0.05$, one-way RM ANOVA). C-fiber-evoked EPSC amplitude stays constant in the presence of IL-1ra alone ( $\boldsymbol{D} ;$ open bar, $p>0.05$, one-way RM ANOVA).

reaching $223 \pm 28 \%$ of baseline (Fig. $3 B$ ). This enhanced synaptic strength in vivo returned to pretreatment values following washout of FKN (Fig. 3B) and was completely prevented by spinal pretreatment with a CX3CR1 neutralizing antibody (Fig. 3C). In contrast, FKN still induced a significant enhancement of synaptic strength following spinal pretreatment with a control IgG (Fig. $3 D$ ). We next used immunohistochemistry to determine whether FKN-induced synaptic facilitation in vivo was a result of quantifiable changes in microglial reactivity. As predicted, the number of Iba-1-positive microglial cells remained unchanged under any condition (Fig. 4). Critically, FKN application induced a significant increase in the percentage of dorsal horn microglia exhibiting immunoreactivity for p-p38 MAPK. In the presence of IgG, the percentage of microglia expressing p-p38 was significantly enhanced 180 min following FKN application, compared with IgG alone, and was comparable to IgG control levels $60 \mathrm{~min}$ following the washout of FKN (Fig. 4A,B). Conversely, when administered in the presence of anti-CX3CR1, FKN application did not lead to any changes in p-p38 levels compared with antiCX3CR1 alone (Fig. 4A,B). Thus, FKN-induced synaptic facili- 
A

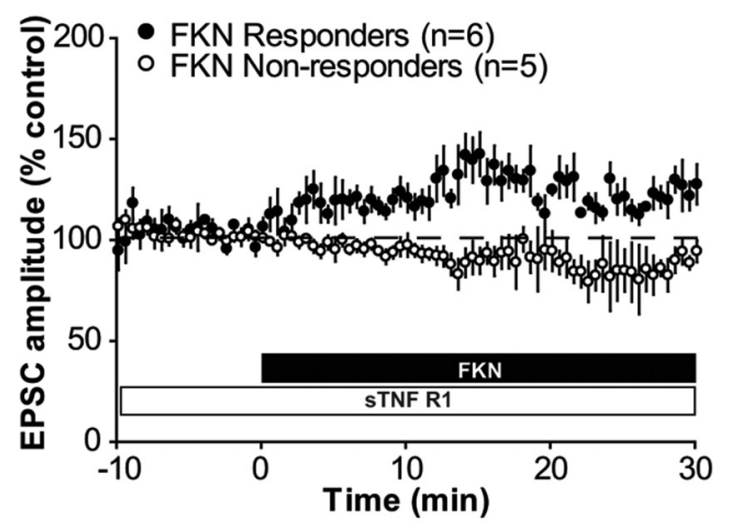

C

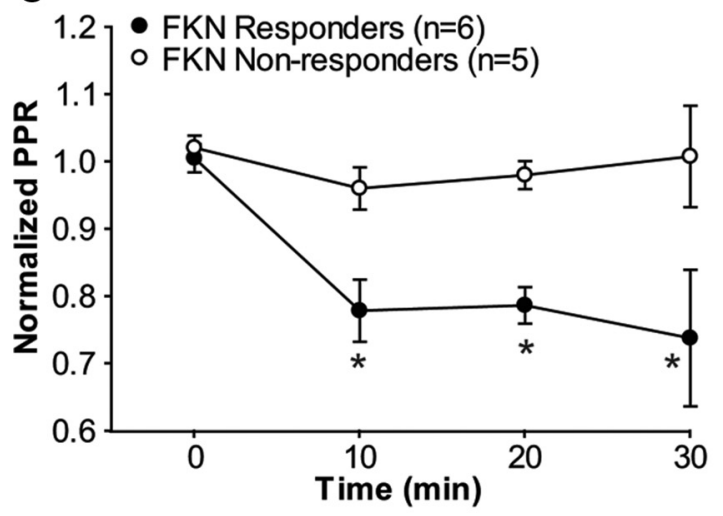

E

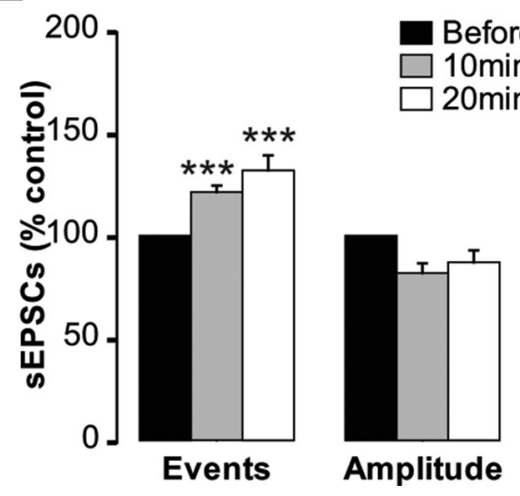

B

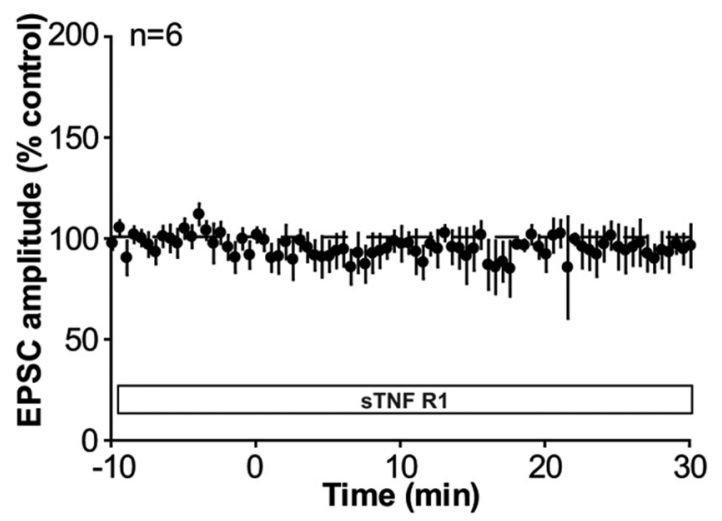

D

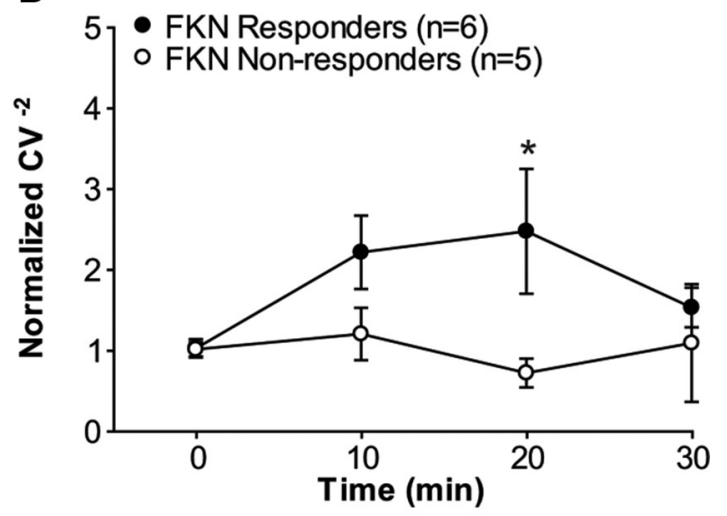


A
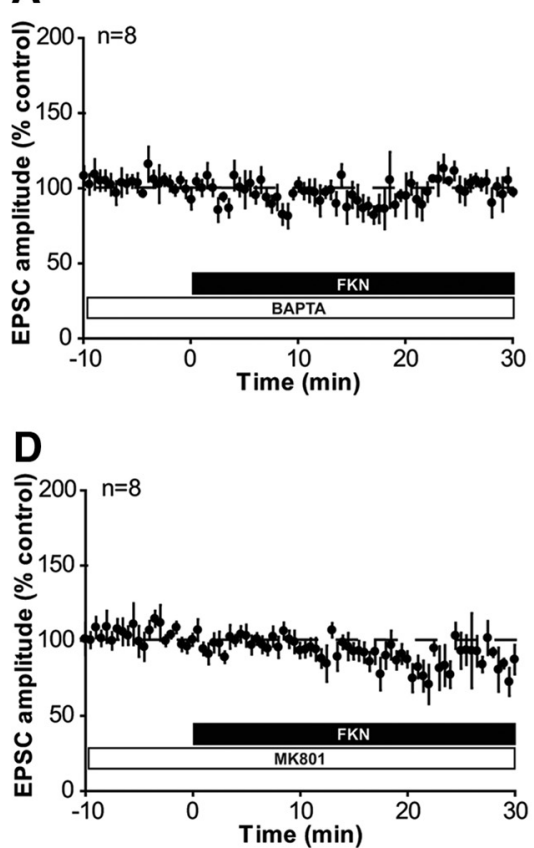

B
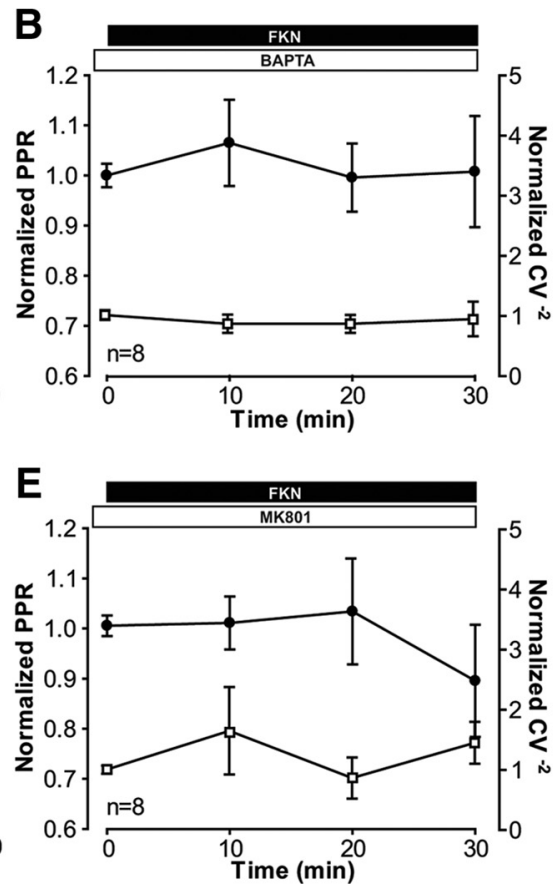
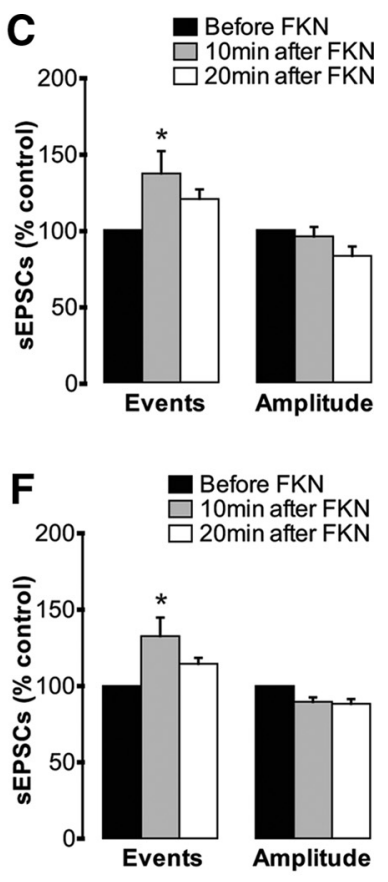

Figure 9. FKN-induced facilitation requires postsynaptic $\mathrm{Ca}^{2+}$ signaling and NMDA receptors. $A-C$, Inclusion of BAPTA (20 mM, open bar) in the pipette solution to block $\mathrm{Ca}^{2+}$ signaling in the postsynaptic neuron completely prevented FKN-induced changes to $C$-fiber-evoked EPSC ( $\boldsymbol{A}), \operatorname{PPR}\left(\boldsymbol{B}\right.$; black circles, left hand axis) and $\mathrm{CV}^{-2}$ ( $\boldsymbol{B}$; white squares, right hand axis), in all neurons tested $\left(\boldsymbol{A}, \boldsymbol{B} ; \boldsymbol{p}>0.05\right.$, one-way RM ANOVA). However, a significant increase in the number of sEPSCs still occurred [ $\boldsymbol{C} ; 136 \pm 14 \%$ at 10 min after FKN application $(n=8) ;{ }^{*} p>0.05$, one-way RM ANOVA]. $\boldsymbol{D}-\boldsymbol{F}$, The addition of MK801 (1 mM, open bar) to the pipette solution in order to specifically inhibit postsynaptic NMDA receptors prevents the effects of FKN on C-fiber-evoked EPSCS (D), PPR (E; black circles, left hand axis), and $C V^{-2}(\boldsymbol{E}$; white squares, right hand axis) in all neurons tested ( $\boldsymbol{D}, \boldsymbol{E} ; \boldsymbol{p}>0.05$, one-way RM ANOVA). However, a significant increase in the number of sEPSCs still occurred $\left[\boldsymbol{F} ; 132 \pm 12 \%\right.$ at $10 \mathrm{~min}$ after FKN $(n=8) ;{ }^{*} p>0.05$, one-way RM ANOVA].

the effects of FKN on both C-fiber-evoked EPSCs (Fig. 6A) and sEPSCs (Fig. 6E) in all neurons tested. FKN-induced changes in PPR (Fig. 6C) and $\mathrm{CV}^{-2}$ (Fig. 6C,D) were also prevented. The presence of minocycline alone did not modify C-fiber-evoked EPSCs (Fig. 6B). Thus, the effect of FKN on synaptic transmission is mediated via microglial CX3CR1 receptors in the dorsal horn of the spinal cord.

Release of a soluble microglial mediator likely arbitrates the changes in synaptic strength observed. We investigated the contribution of two classic proinflammatory cytokines, IL- $1 \beta$ and TNF, since these cytokines are able to modulate synaptic transmission (Kawasaki et al., 2008; Gruber-Schoffnegger et al., 2013). We first examined the release of IL- $1 \beta$ in response to FKN using the spinal dorsal horn preparation with dorsal roots attached. Superfusion of dorsal horn slices with FKN resulted in a significant release of IL- $1 \beta$, reaching $155 \pm 18 \%$ of basal values (Fig. $7 A$ ). In addition, FKN-induced release of IL- $1 \beta$ was completely prevented when dorsal horn slices were incubated with minocycline (Fig. 7A), suggesting that microglia are a likely source of the secreted IL- $1 \beta$. We next studied whether IL- $1 \beta$ release is necessary for FKN-induced facilitation. Indeed, inhibition of IL-1 $\beta$ signaling using IL-1ra was able to completely prevent FKNinduced changes in C-fiber-evoked EPSCs (Fig. 7B), PPR, and $\mathrm{CV}^{-2}$ (Fig. $7 C$ ). The presence of IL-1ra alone did not modify C-fiber-evoked EPSCs (Fig. 7D). Interestingly, in the presence of IL-1ra FKN resulted in a small but significant decrease in the number of sEPSCs (Fig. 7E).

In contrast, the inhibition of TNF signaling using sTNF R1 did not modify FKN-induced facilitation (Fig. 8A). In the presence of sTNF R1, FKN increased synaptic strength at C-fiber synapses in 6 of 11 neurons to $126 \pm 7 \%$ of baseline, whereas sTNF R1 alone did not modify C-fiber-evoked EPSCs (Fig. 8B). In addition, significant
FKN-induced changes in PPR (Fig. 8C), $\mathrm{CV}^{-2}$ (Fig. 8D), and sEPSCs (Fig. $8 E$ ) occurred following sTNF R1. These data suggest that FKNinduced facilitation requires IL- $1 \beta$ signaling, while the role of TNF signaling appears limited under our experimental conditions.

\section{NMDA-dependent postsynaptic mechanisms mediate} FKN-induced facilitation

While changes in PPR, $\mathrm{CV}^{-2}$, and sEPSC frequency suggest a presynaptic expression of FKN-induced synaptic facilitation, we next investigated whether postsynaptic mechanisms contribute to its induction. First, we examined the role of intracellular $\mathrm{Ca}^{2+}$, which is critical for activity-dependent LTP (Ikeda et al., 2003; Ikeda et al., 2006). Indeed, the inclusion of the $\mathrm{Ca}^{2+}$ chelator BAPTA in the pipette solution completely prevented increased synaptic strength at C-fiber synapses following FKN application in all neurons tested (Fig. 9A). No changes in PPR or $\mathrm{CV}^{-2}$ were observed (Fig. 9B). Interestingly, an increase in the number of sEPSCs was still apparent in the absence of postsynaptic $\mathrm{Ca}^{2+}$ (Fig. 9C), suggesting that evoked measures of synaptic strength can be dissociated from changes in spontaneous events.

Second, we examined the contribution of NMDA receptors, the activation of which leads to a large increase in intracellular $\mathrm{Ca}^{2+}$ and can be modulated by IL-1 $\beta$ (Gruber-Schoffnegger et al., 2013). MK801 applied internally at a concentration of $1 \mathrm{~mm}$ used here effectively inhibits NMDA currents in the neuron to which it is applied, with no spillover into the extracellular environment, as neighboring neurons recorded simultaneously demonstrated normal NMDA-mediated currents (Bender et al., 2006). The blockade of postsynaptic NMDA receptors by the addition of MK801 to the pipette solution completely prevented FKN-induced facilitation in all neurons tested (Fig. 9D). FKNinduced changes in PPR and $\mathrm{CV}^{-2}$ were also prevented (Fig. 9E). 
A

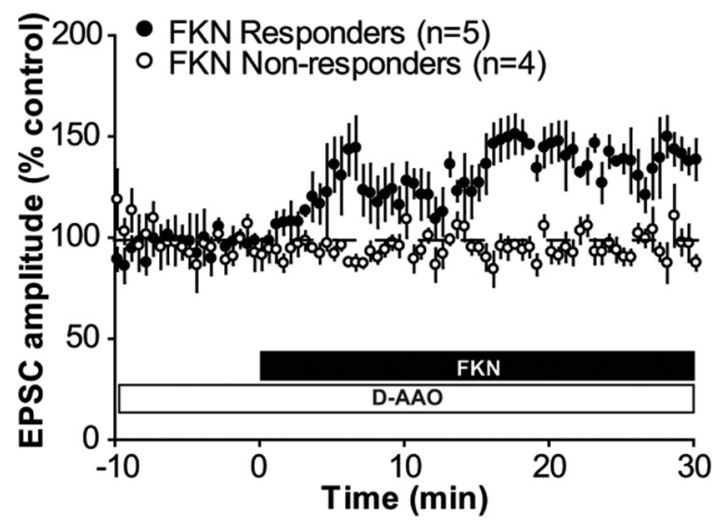

C

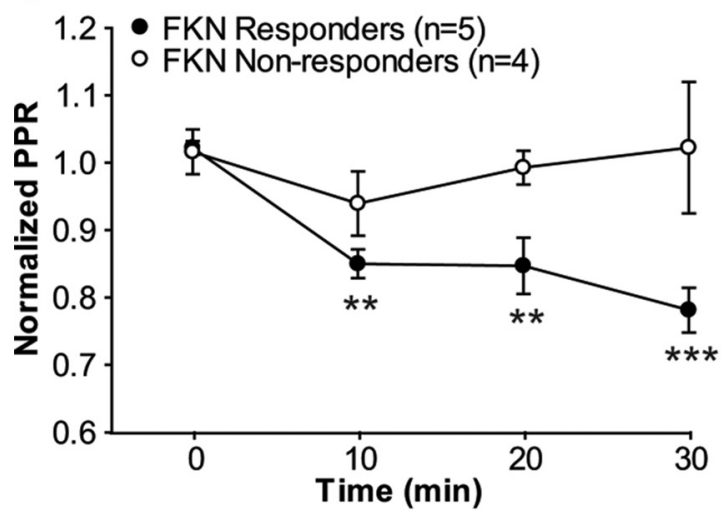

E

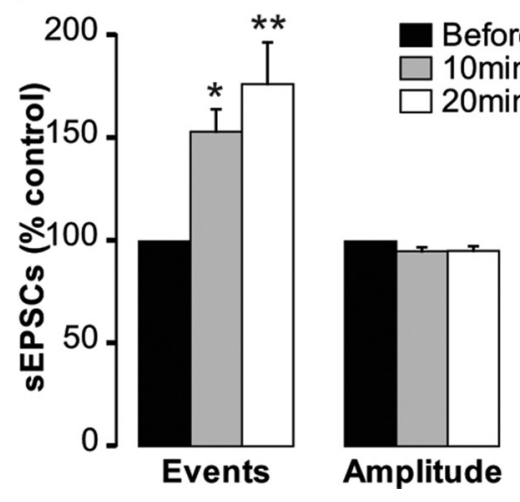

B

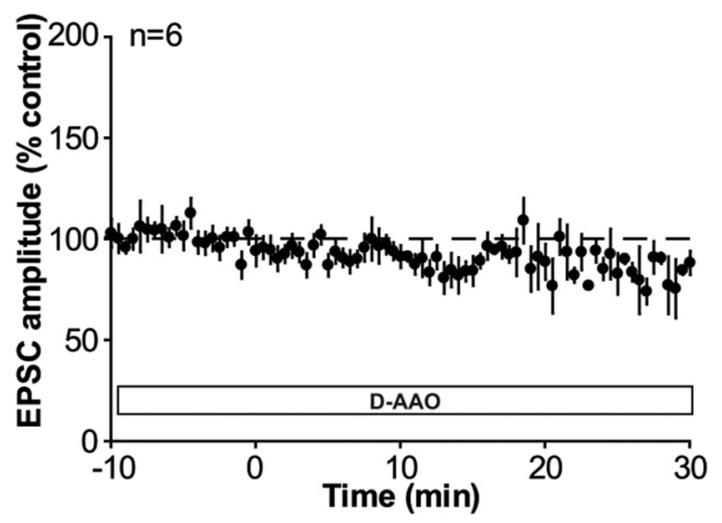

D

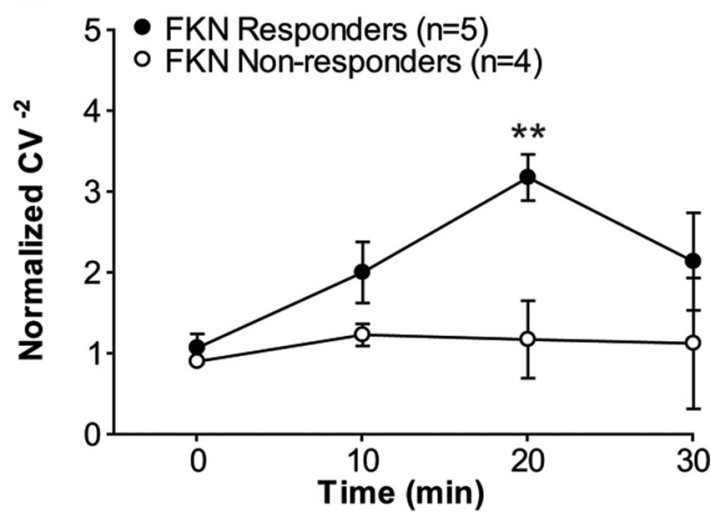

Figure 10. D-Serine is not required for FKN-induced facilitation. $A$, In the presence of D-AAO $(0.2 \mathrm{U} / \mathrm{ml}$ for $1 \mathrm{~h}$ preincubation and the duration of the recording, open bar) to degrade $\mathrm{D}$-serine, FKN (black bar) induced a significant facilitation of C-fiber-evoked EPSC amplitude in five of nine neurons tested [ $138 \pm 5 \%$ at $30 \mathrm{~min}, p<0.001$, one-way ANOVA; $p<0.05$ compared with control cells $(\boldsymbol{B})$, Fisher's exact test]. Filled circles represent neurons showing facilitation; open circles represent neurons showing no change after FKN application. $\boldsymbol{B}$, In six neurons tested, $(-$-fiber-evoked EPSC amplitude stays constant in the presence of D-AA0 alone (open bar, $p>0.05$, one-way RM ANOVA). C, D, Following D-AA0 application, facilitation of C-fiber-evoked EPSCs by FKN is associated with

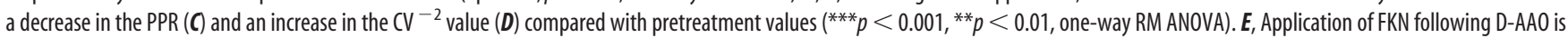
associated with an increase in the number of sEPSCS [153 $\pm 11 \%$ at $10 \mathrm{~min}, 188 \pm 27 \%$ at $20 \mathrm{~min}$ after FKN application $(n=9)]$ compared with pretreatment values $\left({ }^{* *} p<0.01,{ }^{*} p<0.05\right.$, one-way RM ANOVA).

Similar to BAPTA experiments, an increase in the number of sEPSCs was apparent in the presence of postsynaptic MK801 (Fig. $9 F)$. These data suggest that the activation of postsynaptic NMDA receptors and subsequent rises in intracellular $\mathrm{Ca}^{2+} \mathrm{lev}-$ els are necessary for FKN-induced synaptic facilitation, and that evoked measures of synaptic strength can be dissociated from changes in spontaneous events.

In the hippocampus, FKN facilitates NMDA receptor function via D-serine (Scianni et al., 2013). We therefore determined whether D-serine was required for FKN-induced synaptic facilitation at C-fiber synapses. Degradation of endogenous D-serine by the enzyme D-AAO did not modify FKN-induced facilitation (Fig. 10A). Following the incubation of slices with D-AAO, FKN increased synaptic strength at C-fiber synapses in five of nine neurons tested to $138 \pm 5 \%$ of baseline, whereas D-AAO alone did not modify C-fiberevoked EPSCs (Fig. 10B). In addition, significant FKNinduced changes in PPR (Fig. 10C), $\mathrm{CV}^{-2}$ (Fig. 10D), and sEPSCs (Fig. 10E) occurred following D-AAO application. These data suggest that postsynaptic $\mathrm{Ca}^{2+}$ and NMDA recep- 
A
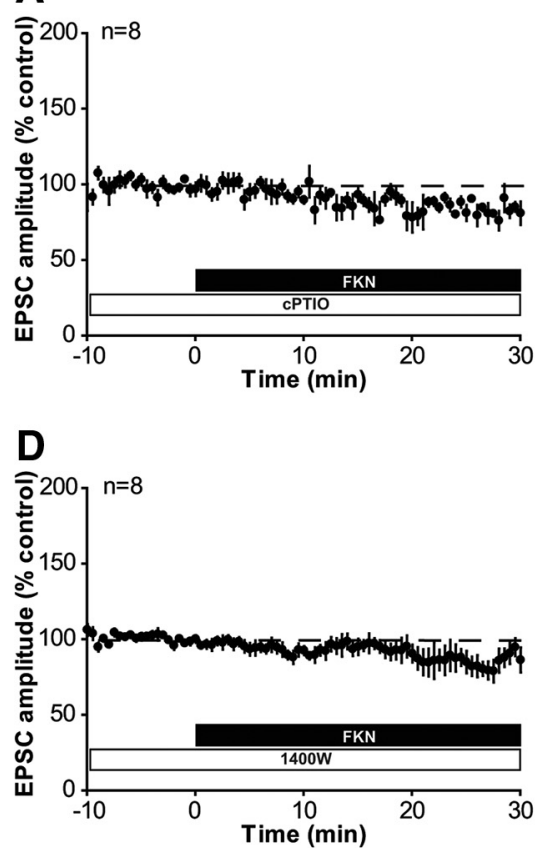

G

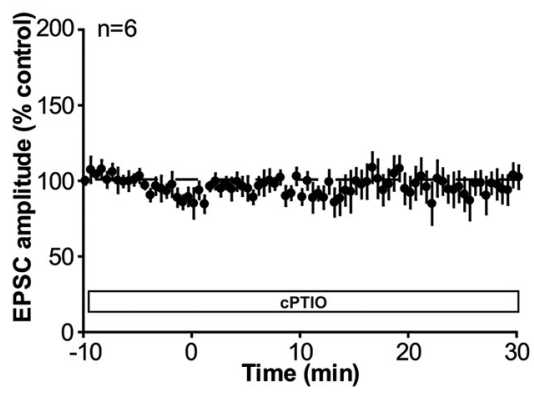

B
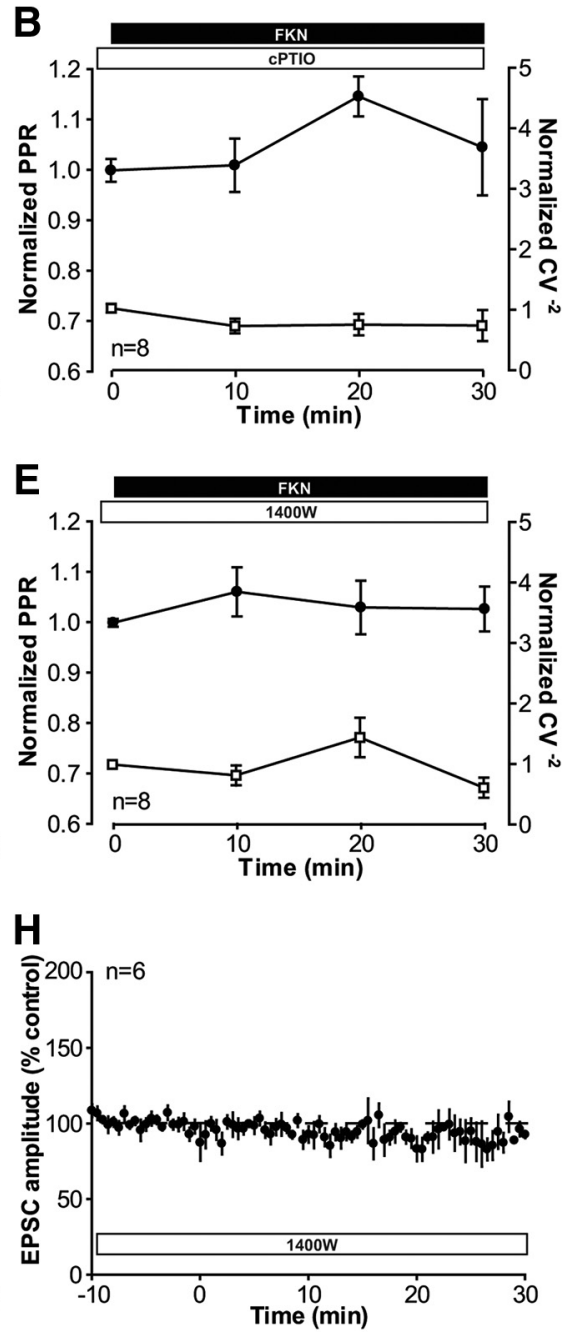

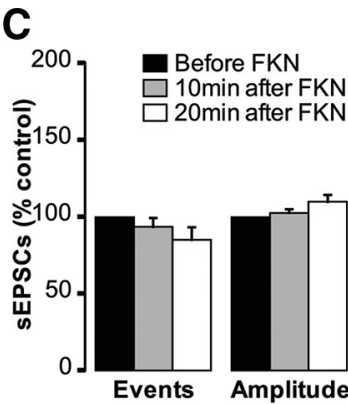

$\mathbf{F}$

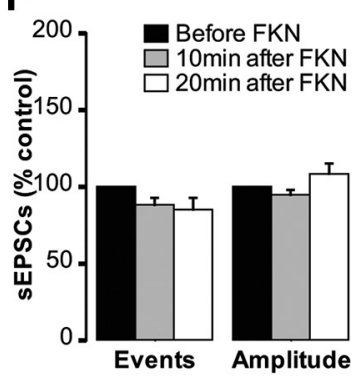

Figure 11. The facilitatory effects of FKN are mediated by NO. $A-C$, In the presence of CPTIO ( $30 \mu \mathrm{m}$ for 30 min preincubation and the duration of the recording, open bar) FKN-induced facilitation of $\left(-\right.$ fiber-evoked EPSC $(\boldsymbol{A})$, changes in PPR ( $\boldsymbol{B}$; black circles, left hand axis) and $\mathrm{CV}^{-2}(\boldsymbol{B}$; white squares, right hand axis), and sEPSCs $(\boldsymbol{C})$ was completely prevented in all neurons tested $(p>0.05$, one-way RM ANOVA). $\boldsymbol{D}-\boldsymbol{F}$, Following incubation of slices with $1400 \mathrm{~W}$ ( $3 \mu \mathrm{m}$ for 30 min preincubation and the duration of the recording, open bar), FKN does not modify $(-$-fiber-evoked EPSCs (D), PPR ( $\boldsymbol{E}$; black circles, left hand axis), $\mathrm{CV}^{-2}$ (E; white squares, right hand axis), or sEPSCS $(\boldsymbol{F})$ in any of the neurons tested ( $p>0.05$, one-way RM ANOVA). $\boldsymbol{G}, \boldsymbol{H}, \mathrm{C}$-fiber-evoked EPSC amplitude stays constant in the presence of $\mathrm{CPTI}$ alone ( $\boldsymbol{G}$; open bar) or $1400 \mathrm{~W}$ alone ( $\boldsymbol{H}$; open bar). $p>0.05$, one-way RM ANOVA.

tors are critical for the induction of synaptic facilitation by FKN; however, D-serine is not required.

\section{Eicosanoids act as possible retrograde messengers during} FKN-induced facilitation

The role of postsynaptic $\mathrm{Ca}^{2+}$ and NMDA receptors for the induction of synaptic facilitation, in combination with changes in parameters that suggest a presynaptic expression, lead us to hypothesize that a retrograde messenger mediates FKN-induced facilitation. A number of candidates have been proposed as retrograde messengers that modulate synaptic transmission. First, we examined the role of nitric oxide (NO), which is critical for activity-dependent LTP at C-fiber synapses (Ikeda et al., 2006). Indeed, the incubation of slices with a membrane-impermeable nitric oxide scavenger (cPTIO) to remove extracellular NO prevented FKN-induced changes in C-fiber-evoked EPSCs (Fig. $11 A$ ), PPR/CV ${ }^{-2}$ (Fig. 11B), and sEPSCs (Fig. 11C) in all neurons tested. A number of cell types within the spinal cord are potential sources of NO, including glial cells, which express inducible NO synthase (iNOS). In the presence of the specific iNOS inhibitor 1400W, FKN no longer modified C-fiber-evoked EPSCs (Fig.
11D), PPR/CV ${ }^{-2}$ (Fig. 11E), or sEPSCs (Fig. 11F) in any neurons tested. Neither cPTIO nor 1400W alone modified C-fiber-evoked EPSC (Fig. 11C,F). From these data, we conclude that the source of NO is unlikely to be the postsynaptic neuron, but is likely to be spinal glial cells, and therefore does not act as a retrograde messenger under our experimental conditions.

We next examined the contribution of arachidonic acid (AA), which is synthesized within neurons following NMDA and $\mathrm{Ca}^{2+}$. dependent activation of phospholipase $\mathrm{A}_{2}$ (PLA $\mathrm{PL}_{2}$; Dumuis et al., 1988; Sanfeliu et al., 1990; Taylor et al., 2008), to FKN-induced synaptic facilitation. AA and its derivatives the prostaglandins (PGs) may act as retrograde messengers in the hippocampus (Williams et al., 1989; Sang et al., 2005). We therefore incubated slices with the $\mathrm{PLA}_{2}$ inhibitor AACOCF3 to prevent the formation of AA, and therefore PGs. AACOCF3 completely prevented FKN-induced changes in C-fiber-evoked EPSCs (Fig. 12A), PPR/ $\mathrm{CV}^{-2}$ (Fig. 12B), and sEPSCs (Fig. 12C) in all neurons tested. AACOCF3 alone did not modify C-fiber-evoked EPSCs (Fig. $12 D$ ). Importantly, in the presence of $0.05 \%$ DMSO (the vehicle control for AACOCF3) FKN increased synaptic strength at C-fiber synapses in five of nine neurons tested to $129 \pm 4 \%$ 
A

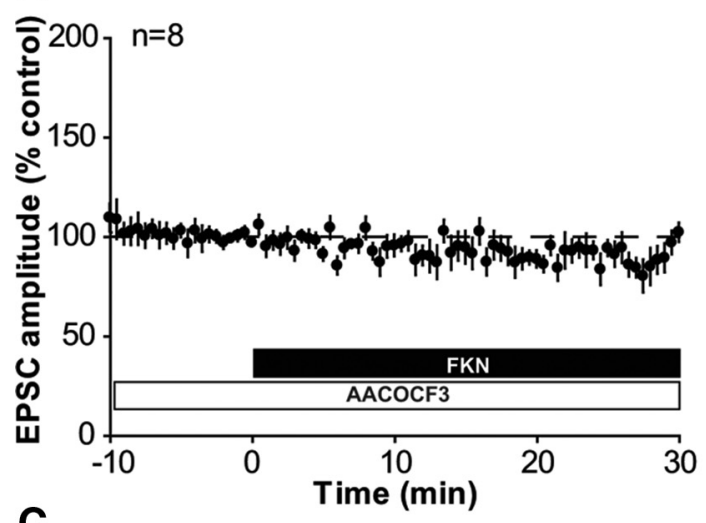

C

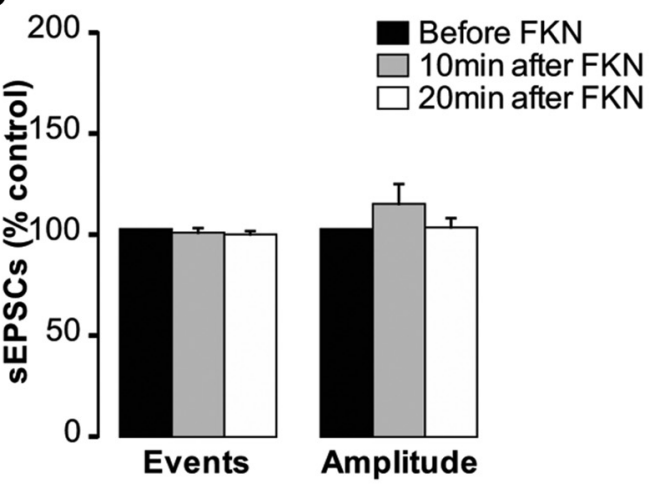

E

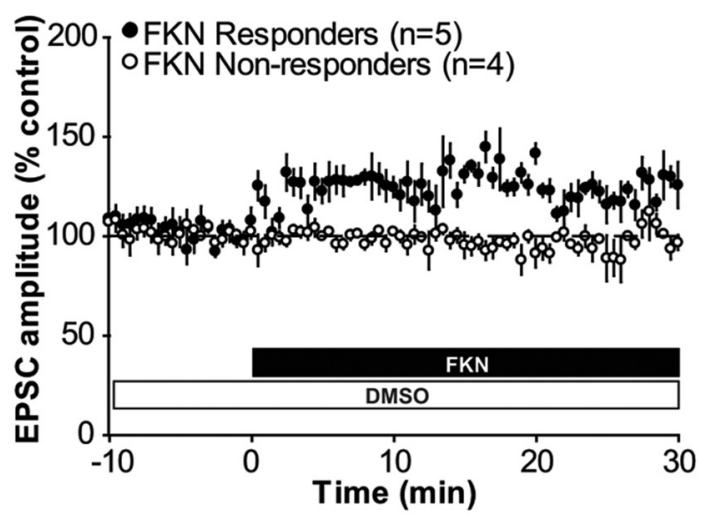

G

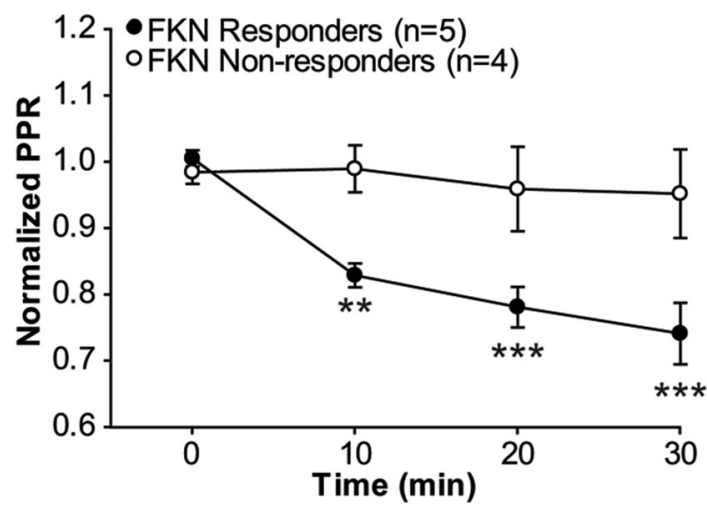

B

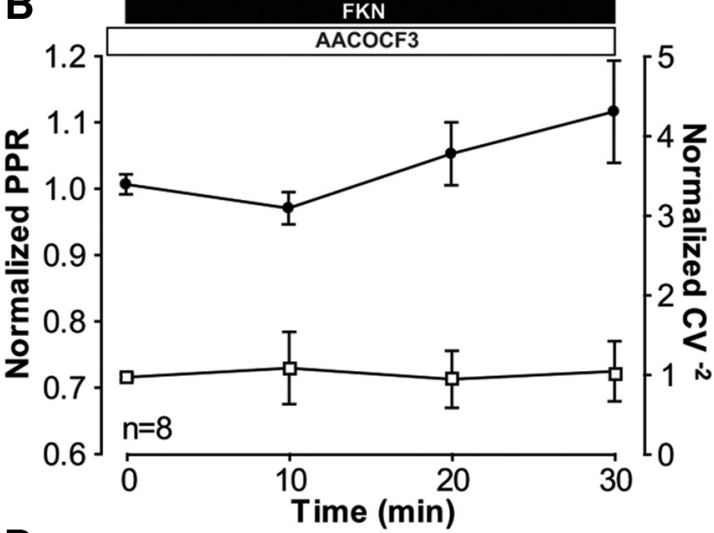

D

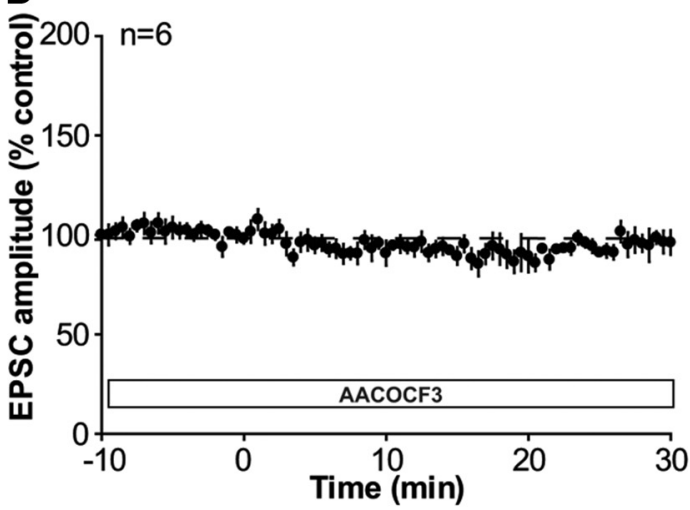

F

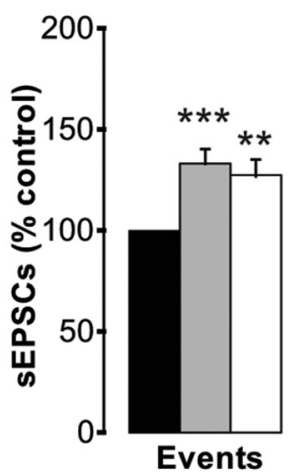

Before FKN

10 min after FKN

20 min after FKN

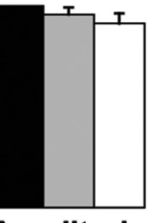

Amplitude

H

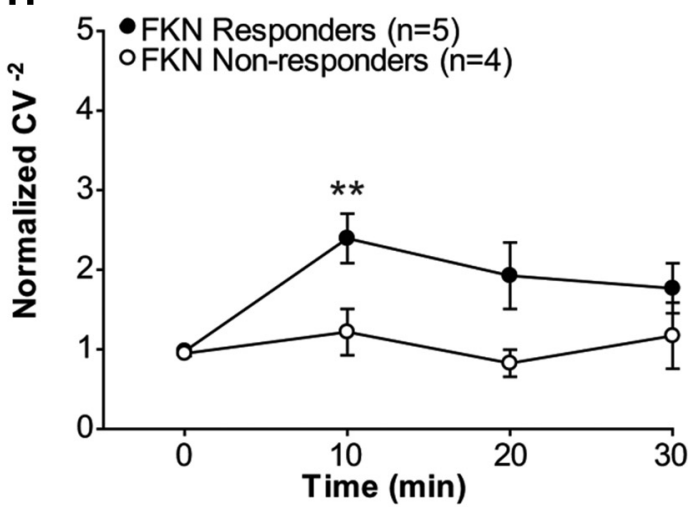

Figure 12. The facilitatory effects of FKN are mediated by $P L A_{2} \cdot A-C$, Inhibition of PLA $(A A C O C F 3 ; 10 \mu \mathrm{m}$ for 20 min preincubation then for the duration of the recording, open bar) prevents the effects of FKN (black bar) on (-fiber-evoked EPSCS ( $\boldsymbol{A})$, PPR ( $\boldsymbol{B}$; black circles, left hand axis), $\mathrm{CV}^{-2}(\boldsymbol{B}$; white squares, right hand axis), and sEPSCs $(\boldsymbol{C})$ in all neurons tested $(p>0.05$, one-way RM ANOVA). D, C-fiber-evoked EPSC amplitude stays constant in the presence of AACOCF3 alone (open bar, $p>0.05$, one-way RM ANOVA). $E$, In the presence of DMSO ( $0.05 \%$ final concentration; for 20 min preincubation then for the duration of the recording, open bar), FKN (black bar) induced a significant facilitation of (-fiber-evoked EPSC amplitude in five of (Figure legend continues.) 
of baseline (Fig. 12E). In addition, significant FKN-induced changes in sEPSCs (Fig. 12F), PPR (Fig. 12G), and $\mathrm{CV}^{-2}$ (Fig. $12 \mathrm{H}$ ) occurred following DMSO application. These data suggest that the effect of FKN on synaptic transmission is mediated via the release of AA/PGs, resulting in enhanced neurotransmitter release from the presynaptic neuron.

These data suggest that NO originating from spinal glia is critical for FKN-induced facilitation; however, it is unlikely that $\mathrm{NO}$ is acting as a retrograde messenger under our experimental condition. In contrast, AA or one of its derivatives may be a critical retrograde signal for $\mathrm{FKN}$-induced facilitation.

\section{Discussion}

We demonstrate that highly selective activation of microglia is sufficient in itself to enhance synaptic strength. Specifically, the stimulation of microglial CX3CR1 receptors using FKN is sufficient to facilitate synaptic strength at the first synapse in the nociceptive pathway. The effect of FKN is rapid, with modifications in synaptic strength observed within minutes of application or washout. Thus, FKN quickly and reversibly enhances synaptic strength in a feedforward manner. This finding is unexpected; it is usually assumed that short-term synaptic plasticity involves essentially presynaptic and postsynaptic neuronal elements. Classic indicators of neuronal mechanisms are requirements for postsynaptic $\mathrm{Ca}^{2+}$ and NMDA receptor activation (Bliss and Collingridge, 1993; Malenka and Bear, 2004), both of which are necessary for FKN-induced facilitation. In contrast, glial activation is considered to be supportive only. Although glial cell activity is necessary for plasticity, it has been suggested recently that the classic mechanisms by which glial cells modulate neurotransmission in the adult be reconsidered (Agulhon et al., 2010; Sun et al., 2013). The present data demonstrate that microglia activation is sufficient for rapidly induced and reversible synaptic modulation.

We propose a flow of signaling cascades, as illustrated in Figure $13 \mathrm{~A}$, resulting in a microglia-driven synaptic facilitation. Specifically, the activation of microglial CX3CR1 receptors in the dorsal horn induces the release of microglial mediators such as IL- $1 \beta$, which act to modulate postsynaptic NMDA receptor function. A rise in intracellular $\mathrm{Ca}^{2+}$ levels in the postsynaptic neuron stimulates the synthesis of AA via $\mathrm{Ca}^{2+}$-dependent $\mathrm{PLA}_{2}$. AA/ PGs feed back onto microglial cells, where they induce iNOS activity resulting in NO production, which enhances presynaptic neurotransmitter release. This signaling cascade for synaptic facilitation contrasts traditional mechanisms required for activity-dependent LTP at C-fiber synapses (Sandkühler, 2009; Gruber-Schoffnegger et al., 2013; summarized in Fig. 13B).

FKN-induced facilitation of synaptic strength comprises postsynaptic induction and presynaptic expression. It remains unclear why postsynaptic NMDA receptors and $\mathrm{Ca}^{2+}$ signaling give rise to short-term plasticity following FKN application, while inducing LTP or LTD under other experimental conditions. The precise spatiotemporal pattern of postsynaptic calcium may de-

\section{$\leftarrow$}

(Figure legend continued.) nine neurons tested [ $125 \pm 4 \%$ at $30 \mathrm{~min}, p<0.01$, one-way ANOVA; $p<0.05$ compared with AACOCF3 cells $(\boldsymbol{A})$, Fisher's exact test]. Filled circles represent neurons showing facilitation; open circles represent neurons showing no change after FKN application. $\boldsymbol{F}$, FKN application following DMSO preincubation is associated with an increase in the number of sEPSCS [132 $\pm 7 \%$ at $10 \mathrm{~min}, 127 \pm 7 \%$ at 20 min after FKN $(n=9)]$ compared with pretreatment values ( ${ }^{* *} p<0.01$, one-way RM ANOVA). $\mathbf{G}, \boldsymbol{H}$, Following DMSO application, facilitation of C-fiber-evoked EPSCS by FKN is associated with a decrease in the PPR $(\boldsymbol{G})$ and an increase in the $\mathrm{CV}^{-2}$ value $(\boldsymbol{H})$ compared with pretreatment values $\left({ }^{*} p<0.05,{ }^{* *} p<0.01\right.$, one-way RM ANOVA). termine which intracellular signaling pathways are activated and therefore how synaptic strength is modulated (Malenka et al., 1992; Sheng and Kim, 2002). Interestingly, in the hippocampus, FKN/CX3CR1 signaling depresses excitatory synaptic transmission via NMDA-independent postsynaptic mechanisms (Ragozzino et al., 2006) and impairs LTP (Maggi et al., 2009). This is in line with the divergent neuroprotective effects of CX3CR1-expressing microglia in the brain (Cardona et al., 2006) versus the pronociceptive effects of CX3CR1-expressing microglia in the spinal cord (Milligan et al., 2004, 2005; Clark et al., 2007, 2012; Zhuang et al., 2007), which are likely mediated via distinct intracellular signaling pathways. Indeed, $\mathrm{FKN} / \mathrm{CX} 3 \mathrm{CR} 1$ signaling is neuroprotective via ERK and phosphoinositide 3 kinase pathways (Limatola et al., 2005) and inhibition of cytokine release (Cardona et al., 2006). In contrast, CX3CR1 deficiency prevents the development of chronic pain (Staniland et al., 2010). The pronociceptive effects of FKN/CX3CR1 signaling are mediated by $\mathrm{p} 38$ MAPK and the release of cytokines (Milligan et al., 2005; Clark et al., 2007; Zhuang et al., 2007). Interestingly, in the hippocampus, FKN facilitates NMDA receptor currents via D-serine (Scianni et al., 2013). We found no role for D-serine in FKN-induced synaptic facilitation, further highlighting the divergent mechanisms by which FKN modulates excitatory transmission and the distinct phenotypes of glial cells in different CNS regions (Hanisch and Kettenmann, 2007). Indeed, glia cell contribution to synaptic transmission differs greatly between the brain and spinal cord (Ben Achour and Pascual, 2010; Zhong et al., 2010; GruberSchoffnegger et al., 2013).

Here we have delineated mechanisms by which specific microglial signaling pathways can dynamically modulate synaptic strength. CX3CR1 receptor activation results in the release of IL- $1 \beta$ in the dorsal horn, which is critical for FKN-induced facilitation. Interestingly, despite IL- $1 \beta$ directly enhancing NMDA receptor phosphorylation in the dorsal horn (Gruber-Schoffnegger et al., 2013), its effects on neuronal excitability may occur via an indirect glial mechanism (Constandil et al., 2009; GruberSchoffnegger et al., 2013; Liu et al., 2013), potentially by inducing the release of a cocktail of proinflammatory cytokines (GruberSchoffnegger et al., 2013). An essential need for glial cell activity in cytokine-mediated neuronal plasticity is in line with the microglia-arbitrated facilitation reported here. Exogenous levels of IL- $1 \beta$ applied previously are much higher than the endogenous levels measured here following FKN application, potentially accounting for the LTP reported following exogenous IL- $1 \beta$ application (Gruber-Schoffnegger et al., 2013) versus the short-term plasticity observed following FKN application. It is currently unclear how the extracellular cytokine composition following FKN application, which includes IL- $1 \beta$, relates to that after exogenous IL- $1 \beta$ application. In contrast, we found no evidence for TNFR1 signaling during $\mathrm{FKN}$-induced facilitation under our experimental conditions; however, the contribution of TNFR2 remains unknown. Glia-derived TNF has been proposed to enhance spinal excitatory synaptic transmission under other experimental conditions (Gruber-Schoffnegger et al., 2013; Berta et al., 2014). The contributions of IL- $1 \beta$ and TNF to FKN-induced facilitation may be due to the extensive phenotypic diversity of microglia (Hanisch and Kettenmann, 2007). Thus, different microglia-activating stimuli may result in different mixtures of gliotransmitters and, therefore, in diverse effects on synaptic transmission.

The data presented here indicate that FKN-induced release of IL-1 $\beta$ from microglia modulates postsynaptic NMDA receptor function, resulting in increased intracellular $\mathrm{Ca}^{2+}$ levels and synthesis of AA/PGs, via $\mathrm{PLA}_{2}$. Both AA and PGs act as retrograde 
messengers in the hippocampus (Williams et al., 1989; Sang et al., 2005). Several lines of evidence suggest that the source of AA/PGs in the dorsal horn is the postsynaptic neuron, rather than glial cells. First, in the naive spinal cord, PLA $_{2}$ expression is neuronal (Ong et al., 1999; Kim et al., 2008), not glial (Kim et al., 2008), with microglial expression occurring only following injury (Liu et al., 2006). Second, NMDA receptor activation induces $\mathrm{Ca}^{2+}$-dependent, $\mathrm{PLA}_{2}$ dependent release of both AA and PGs from neurons, but not from astrocytes (Taylor et al., 2008). PGs may act to enhance synaptic transmission by acting directly on the presynaptic neuron (Minami et al., 1999); however, we suggest that following FKN application PGs induce the expression of iNOS in glial cells; iNOS expression is observed in spinal glial cells, but not in spinal neurons (Dauch et al., 2012). Thus, we suggest that during FKNinduced facilitation $\mathrm{NO}$ acts as a glial signaling factor, not a retrograde messenger. This hypothesis is supported by known interactions between iNOS and PGs (Minami et al., 1995; Gühring et al., 2000). Therefore, PG-induced release of NO from glia may act to modulate presynaptic activity, as intracellular targets of NO within the primary afferent terminal are critical for spinal LTP (Luo et al., 2012). Each individual component of the signaling cascades delineated here is known to modulate nociceptive transmission in vivo. $\mathrm{PLA}_{2}$ critically contributes to inflammatory pain states, with neuronal PG release regulated by IL- $1 \beta$ and NMDA receptor activation (Malmberg and Yaksh, 1992; Samad et al., 2001; Svensson and Yaksh, 2002; Lucas et al., 2005).

A role for neuron-microglia communication in chronic pain states is now well established (Clark and Malcangio, 2012; Ji et al., 2013; Xanthos and Sandkühler, 2014). Microglial mediators can modulate synaptic transmission (Coull et al., 2005; Gruber-Schoffnegger et al., 2013; Berta et al., 2014); however, the mechanisms remain to be fully determined. Here we provide direct evidence that a microglia-specific receptor modulates synaptic transmission in the dorsal horn, providing mechanistic insight, which has been lacking until now. The microglial chemokine receptor CX3CR1 is a promising therapeutic target for chronic pain treatment (Clark et al., 2011; Clark and Malcangio, 2014). Intrathecal FKN induces pain hypersensitivity in naive rodents (Milligan et al., 2004, 2005; Clark et al., 2007; Zhuang et al., 2007) via stimulation of a CX3CR1enhanced response state in microglia
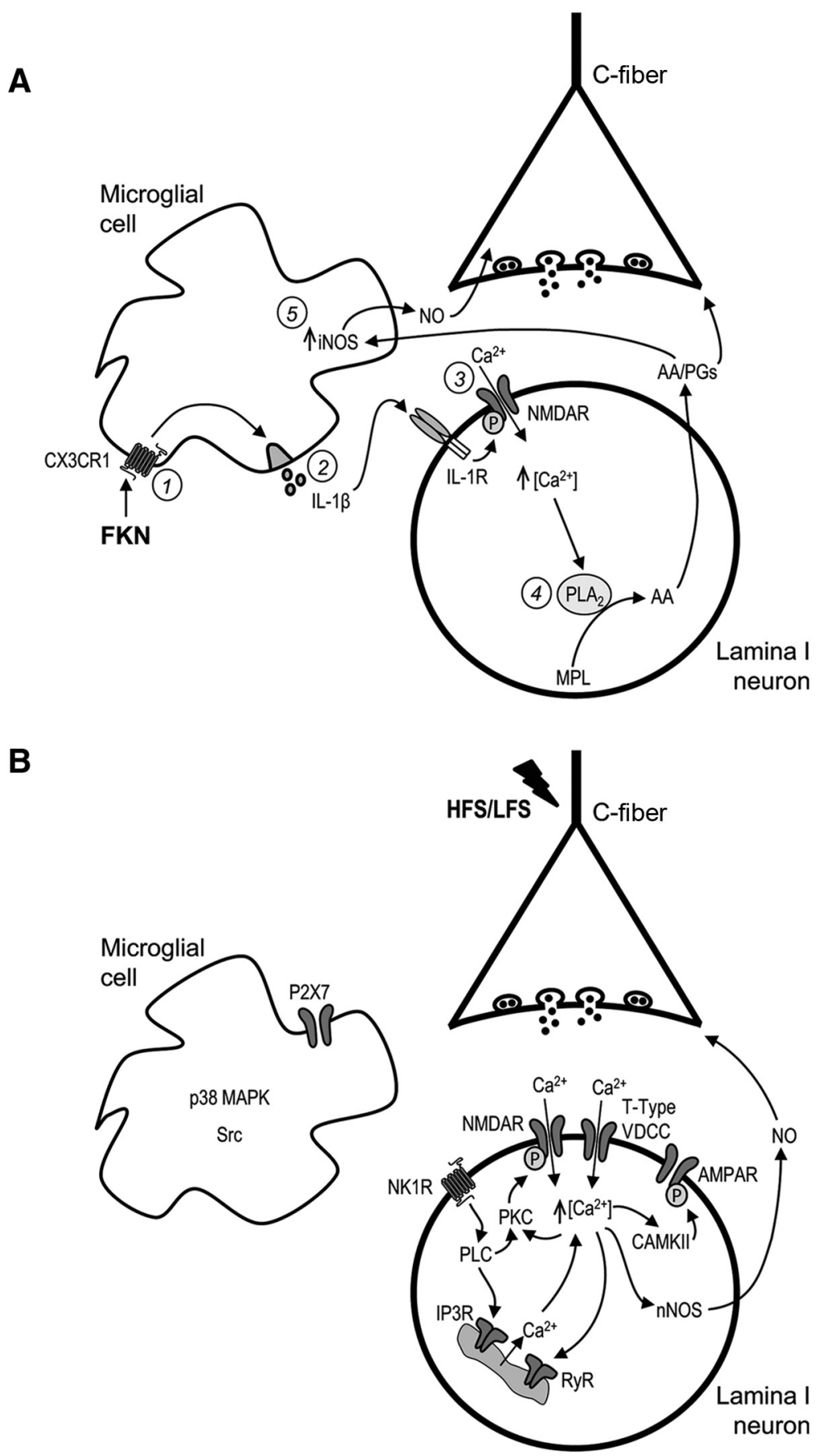

Figure 13. Schematic of the proposed mechanism of FKN-induced synaptic facilitation. $A$, We propose a novel mechanism by which FKN induces synaptic facilitation. Activation of microglial CX3CR1 receptors (1) results in the release of IL-1 $\beta$ (2), which acts to modulate postsynaptic NMDA receptors (3). Increased intracellular $\mathrm{Ca}^{2+}$ in the postsynaptic neuron stimulates synthesis of AA via PLA ${ }_{2}$ (4). AA/PGs feed back onto the microglial cells, where they induce iNOS activity and subsequent NO production (5), which modulates presynaptic neurotransmitter release. AA/PGs may also act directly on the presynaptic neuron. MPL, Membrane phospholipids. $\boldsymbol{B}$, The proposed mechanism of FKN-induced facilitation is in contrast with the traditional mechanisms of activitydependent LTP. At synapses between C-fibers and lamina I neurons, HFS/LFS triggers the release of the excitatory neurotransmitters glutamate and substance $P$, leading to depolarization of the postsynaptic cell. Potentiation of synaptic strength requires activation of T-type VDCCs (leading to $\mathrm{Ca}^{2+}$ influx), NK1 receptors, release of $\mathrm{Ca}^{2+}$ from intracellular stores, and activation of intracellular proteases, including PLC, PKC, and CaMKII, which lead to the phosphorylation of glutamate receptors. Several microglial signaling mechanisms may also contribute, including the P2X7 receptor and intracellular signaling via p38 MAPK and Src. AMPAR, AMPA receptor; CaMKII, $\mathrm{Ca}^{2+}$-calmodulin dependent kinase II; HFS, high-frequency stimulation; IP3R, inositol 1,4,5trisphosphate receptor; LFS, low-frequency stimulation; NK1R, neurokinin receptor 1;NMDAR, NMDA receptor; nNOS, neuronal nitric oxide synthase; PKC, protein kinase C; PLC, phospholipase C; RyR, ryanodine receptor; VDCC, voltage-dependent $\mathrm{Ca}^{2+}$ channel. 
(Clark et al., 2007) and the subsequent release of proinflammatory mediators, including IL- $1 \beta$ and NO (Milligan et al., 2005). In the dorsal horn, neuronal transmembrane FKN is proteolytically cleaved by CatS into soluble FKN that is pronociceptive (Clark et al., 2007). Thus, the liberation of soluble FKN occurs in the dorsal horn only when microglia are in a reactive state, with electrical stimulation of primary afferent fibers under naive conditions insufficient to induce FKN liberation (Clark et al., 2009). Thus, as with the short-term plasticity described here, FKN liberation in vivo requires microglia reactivity, with neuronal activity alone being insufficient. Consistently, inhibition of CatS/FKN/CX3CR1 attenuates neuropathic and inflammatory pain hypersensitivity (Milligan et al., 2004; Clark et al., 2007, 2012; Zhuang et al., 2007; Staniland et al., 2010). Critically, we now demonstrate that soluble FKN-induced activation of microglial CX3CR1 is sufficient to modulate synaptic transmission in the dorsal horn; thus, microglial cells are capable of inducing synaptic facilitation in the absence of enhanced neuronal activity. Indeed, such a situation may occur in vivo following microglia-activating stimuli in the absence of direct neuronal injury, such as during infection or neuroinflammation. Under such circumstances, the continuous presence of FKN would maintain facilitation by continuously driving microglia reactivity, and thereby enhancing nociceptive transmission.

In summary, we demonstrate a previously undescribed form of short-term plasticity, whereby microglial cell activity is sufficient for synaptic facilitation. Such a pronociceptive mechanism would contribute to neuron-microglia positive feedback during chronic pain and would reinforce the proposal that CX3CR1 receptor antagonists would be beneficial for chronic pain treatment.

\section{References}

Agulhon C, Fiacco TA, McCarthy KD (2010) Hippocampal short- and longterm plasticity are not modulated by astrocyte $\mathrm{Ca} 2+$ signaling. Science 327:1250-1254. CrossRef Medline

Ben Achour S, Pascual O (2010) Glia: the many ways to modulate synaptic plasticity. Neurochem Int 57:440-445. CrossRef Medline

Bender VA, Bender KJ, Brasier DJ, Feldman DE (2006) Two coincidence detectors for spike timing-dependent plasticity in somatosensory cortex. J Neurosci 26:4166-4177. CrossRef Medline

Berta T, Park CK, Xu ZZ, Xie RG, Liu T, Lü N, Liu YC, Ji RR (2014) Extracellular caspase- 6 drives murine inflammatory pain via microglial TNFalpha secretion. J Clin Invest 124:1173-1186. CrossRef Medline

Bliss TV, Collingridge GL (1993) A synaptic model of memory: long-term potentiation in the hippocampus. Nature 361:31-39. CrossRef Medline

Cardona AE, Pioro EP, Sasse ME, Kostenko V, Cardona SM, Dijkstra IM, Huang D, Kidd G, Dombrowski S, Dutta R, Lee JC, Cook DN, Jung S, Lira SA, Littman DR, Ransohoff RM (2006) Control of microglial neurotoxicity by the fractalkine receptor. Nat Neurosci 9:917-924. CrossRef Medline

Clark AK, Malcangio M (2012) Microglial signalling mechanisms: cathep$\sin$ S and fractalkine. Exp Neurol 234:283-292. CrossRef Medline

Clark AK, Malcangio M (2014) Fractalkine/CX3CR1 signaling during neuropathic pain. Front Cell Neurosci 8:121. CrossRef Medline

Clark AK, D’Aquisto F, Gentry C, Marchand F, McMahon SB, Malcangio M (2006) Rapid co-release of interleukin 1 beta and caspase 1 in spinal cord inflammation. J Neurochem 99:868-880. CrossRef Medline

Clark AK, Yip PK, Grist J, Gentry C, Staniland AA, Marchand F, Dehvari M, Wotherspoon G, Winter J, Ullah J, Bevan S, Malcangio M (2007) Inhibition of spinal microglial cathepsin $\mathrm{S}$ for the reversal of neuropathic pain. Proc Natl Acad Sci U S A 104:10655-10660. CrossRef Medline

Clark AK, Yip PK, Malcangio M (2009) The liberation of fractalkine in the dorsal horn requires microglial cathepsin S. J Neurosci 29:6945-6954. CrossRef Medline

Clark AK, Staniland AA, Marchand F, Kaan TK, McMahon SB, Malcangio M (2010) P2X7-Dependent release of interleukin-1 $\beta$ and nociception in the spinal cord following lipopolysaccharide. J Neurosci 30:573-582. CrossRef Medline

Clark AK, Staniland AA, Malcangio M (2011) Fractalkine/CX3CR1 signal- ling in chronic pain and inflammation. Curr Pharm Biotechnol 12:17071714. CrossRef Medline

Clark AK, Grist J, Al-Kashi A, Perretti M, Malcangio M (2012) Spinal cathepsin S and fractalkine contribute to chronic pain in the collageninduced arthritis model. Arthritis Rheum 64:2038-2047. CrossRef Medline

Constandil L, Hernández A, Pelissier T, Arriagada O, Espinoza K, Burgos H, Laurido C (2009) Effect of interleukin-1beta on spinal cord nociceptive transmission of normal and monoarthritic rats after disruption of glial function. Arthritis Res Ther 11:R105. CrossRef Medline

Coull JA, Beggs S, Boudreau D, Boivin D, Tsuda M, Inoue K, Gravel C, Salter MW, De Koninck Y (2005) BDNF from microglia causes the shift in neuronal anion gradient underlying neuropathic pain. Nature 438:10171021. CrossRef Medline

Dauch JR, Yanik BM, Hsieh W, Oh SS, Cheng HT (2012) Neuron-astrocyte signaling network in spinal cord dorsal horn mediates painful neuropathy of type 2 diabetes. Glia 60:1301-1315. CrossRef Medline

Dodt HU, Zieglgänsberger W (1990) Visualizing unstained neurons in living brain slices by infrared DIC-videomicroscopy. Brain Res 537:333336. CrossRef Medline

Drdla R, Gassner M, Gingl E, Sandkühler J (2009) Induction of synaptic long-term potentiation after opioid withdrawal. Science 325:207-210. CrossRef Medline

Drdla-Schutting R, Benrath J, Wunderbaldinger G, Sandkühler J (2012) Erasure of a spinal memory trace of pain by a brief, high-dose opioid administration. Science 335:235-238. CrossRef Medline

Dumuis A, Sebben M, Haynes L, Pin JP, Bockaert J (1988) NMDA receptors activate the arachidonic acid cascade system in striatal neurons. Nature 336:68-70. CrossRef Medline

Gruber-Schoffnegger D, Drdla-Schutting R, Hönigsperger C, Wunderbaldinger G, Gassner M, Sandkühler J (2013) Induction of thermal hyperalgesia and synaptic long-term potentiation in the spinal cord lamina I by TNF- $\alpha$ and IL- $1 \beta$ is mediated by glial cells. J Neurosci 33:6540-6551. CrossRef Medline

Gühring H, Görig M, Ates M, Coste O, Zeilhofer HU, Pahl A, Rehse K, Brune K (2000) Suppressed injury-induced rise in spinal prostaglandin E2 production and reduced early thermal hyperalgesia in iNOS-deficient mice. J Neurosci 20:6714-6720. Medline

Hanisch UK, Kettenmann H (2007) Microglia: active sensor and versatile effector cells in the normal and pathologic brain. Nat Neurosci 10:13871394. CrossRef Medline

Humeau Y, Shaban H, Bissière S, Lüthi A (2003) Presynaptic induction of heterosynaptic associative plasticity in the mammalian brain. Nature 426 : 841-845. CrossRef Medline

Ikeda H, Heinke B, Ruscheweyh R, Sandkühler J (2003) Synaptic plasticity in spinal lamina I projection neurons that mediate hyperalgesia. Science 299:1237-1240. CrossRef Medline

Ikeda H, Stark J, Fischer H, Wagner M, Drdla R, Jäger T, Sandkühler J (2006) Synaptic amplifier of inflammatory pain in the spinal dorsal horn. Science 312:1659-1662. CrossRef Medline

Ji RR, Berta T, Nedergaard M (2013) Glia and pain: is chronic pain a gliopathy? Pain 154 [Suppl 1]:S10-S28. CrossRef Medline

Kawasaki Y, Zhang L, Cheng JK, Ji RR (2008) Cytokine mechanisms of central sensitization: distinct and overlapping role of interleukin- $1 \beta$, interleukin-6, and tumor necrosis factor- $\alpha$ in regulating synaptic and neuronal activity in the superficial spinal cord. J Neurosci 28:5189-5194. CrossRef Medline

Kim DH, Fitzsimmons B, Hefferan MP, Svensson CI, Wancewicz E, Monia BP, Hung G, Butler M, Marsala M, Hua XY, Yaksh TL (2008) Inhibition of spinal cytosolic phospholipase A(2) expression by an antisense oligonucleotide attenuates tissue injury-induced hyperalgesia. Neuroscience 154:1077-1087. CrossRef Medline

Limatola C, Lauro C, Catalano M, Ciotti MT, Bertollini C, Di Angelantonio S, Ragozzino D, Eusebi F (2005) Chemokine CX3CL1 protects rat hippocampal neurons against glutamate-mediated excitotoxicity. J Neuroimmunol 166:19-28. CrossRef Medline

Liu NK, Zhang YP, Titsworth WL, Jiang X, Han S, Lu PH, Shields CB, Xu XM (2006) A novel role of phospholipase A2 in mediating spinal cord secondary injury. Ann Neurol 59:606-619. CrossRef Medline

Liu T, Jiang CY, Fujita T, Luo SW, Kumamoto E (2013) Enhancement by interleukin-1beta of AMPA and NMDA receptor-mediated currents in 
adult rat spinal superficial dorsal horn neurons. Mol Pain 9:16. CrossRef Medline

Lucas KK, Svensson CI, Hua XY, Yaksh TL, Dennis EA (2005) Spinal phospholipase A2 in inflammatory hyperalgesia: role of group IVA cPLA2. Br J Pharmacol 144:940-952. CrossRef Medline

Luo C, Gangadharan V, Bali KK, Xie RG, Agarwal N, Kurejova M, TappeTheodor A, Tegeder I, Feil S, Lewin G, Polgar E, Todd AJ, Schlossmann J, Hofmann F, Liu DL, Hu SJ, Feil R, Kuner T, Kuner R (2012) Presynaptically localized cyclic GMP-dependent protein kinase 1 is a key determinant of spinal synaptic potentiation and pain hypersensitivity. PLoS Biol 10:e1001283. CrossRef Medline

Maggi L, Trettel F, Scianni M, Bertollini C, Eusebi F, Fredholm BB, Limatola C (2009) LTP impairment by fractalkine/CX3CL1 in mouse hippocampus is mediated through the activity of adenosine receptor type 3 (A3R). J Neuroimmunol 215:36-42. CrossRef Medline

Malenka RC, Bear MF (2004) LTP and LTD: an embarrassment of riches. Neuron 44:5-21. CrossRef Medline

Malenka RC, Lancaster B, Zucker RS (1992) Temporal limits on the rise in postsynaptic calcium required for the induction of long-term potentiation. Neuron 9:121-128. CrossRef Medline

Malmberg AB, Yaksh TL (1992) Hyperalgesia mediated by spinal glutamate or substance P receptor blocked by spinal cyclooxygenase inhibition. Science 257:1276-1279. CrossRef Medline

Milligan ED, Zapata V, Chacur M, Schoeniger D, Biedenkapp J, O'Connor KA, Verge GM, Chapman G, Green P, Foster AC, Naeve GS, Maier SF, Watkins LR (2004) Evidence that exogenous and endogenous fractalkine can induce spinal nociceptive facilitation in rats. Eur J Neurosci 20:2294-2302. CrossRef Medline

Milligan E, Zapata V, Schoeniger D, Chacur M, Green P, Poole S, Martin D, Maier SF, Watkins LR (2005) An initial investigation of spinal mechanisms underlying pain enhancement induced by fractalkine, a neuronally released chemokine. Eur J Neurosci 22:2775-2782. CrossRef Medline

Minami T, Nishihara I, Ito S, Sakamoto K, Hyodo M, Hayaishi O (1995) Nitric oxide mediates allodynia induced by intrathecal administration of prostaglandin E2 or prostaglandin F2 alpha in conscious mice. Pain 61: 285-290. CrossRef Medline

Minami T, Okuda-Ashitaka E, Hori Y, Sakuma S, Sugimoto T, Sakimura K, Mishina M, Ito S (1999) Involvement of primary afferent C-fibres in touch-evoked pain (allodynia) induced by prostaglandin E2. Eur J Neurosci 11:1849-1856. CrossRef Medline

Naka A, Gruber-Schoffnegger D, Sandkühler J (2013) Non-Hebbian plasticity at C-fiber synapses in rat spinal cord lamina I neurons. Pain 154: 1333-1342. CrossRef Medline

Ong WY, Horrocks LA, Farooqui AA (1999) Immunocytochemical localization of CPLA2 in rat and monkey spinal cord. J Mol Neurosci 12:123130. CrossRef Medline

Park CK, Lü N, Xu ZZ, Liu T, Serhan CN, Ji RR (2011) Resolving TRPV1and TNF- $\alpha$-mediated spinal cord synaptic plasticity and inflammatory pain with neuroprotectin D1. J Neurosci 31:15072-15085. CrossRef Medline

Paxinos G, Watson C (1982) The rat brain in stereotaxic coordinates. San Diego, CA: Academic.

Ragozzino D, Di Angelantonio S, Trettel F, Bertollini C, Maggi L, Gross C, Charo IF, Limatola C, Eusebi F (2006) Chemokine fractalkine/CX3CL1 negatively modulates active glutamatergic synapses in rat hippocampal neurons. J Neurosci 26:10488-10498. CrossRef Medline
Samad TA, Moore KA, Sapirstein A, Billet S, Allchorne A, Poole S, Bonventre JV, Woolf CJ (2001) Interleukin-1beta-mediated induction of Cox-2 in the CNS contributes to inflammatory pain hypersensitivity. Nature 410: 471-475. CrossRef Medline

Sandkühler J (2009) Models and mechanisms of hyperalgesia and allodynia. Physiol Rev 89:707-758. CrossRef Medline

Sanfeliu C, Hunt A, Patel AJ (1990) Exposure to N-methyl-D-aspartate increases release of arachidonic acid in primary cultures of rat hippocampal neurons and not in astrocytes. Brain Res 526:241-248. CrossRef Medline

Sang N, Zhang J, Marcheselli V, Bazan NG, Chen C (2005) Postsynaptically synthesized prostaglandin E2 (PGE2) modulates hippocampal synaptic transmission via a presynaptic PGE2 EP2 receptor. J Neurosci 25:98589870. CrossRef Medline

Scianni M, Antonilli L, Chece G, Cristalli G, Di Castro MA, Limatola C, Maggi L (2013) Fractalkine (CX3CL1) enhances hippocampal N-methyl-daspartate receptor (NMDAR) function via d-serine and adenosine receptor type A2 (A2AR) activity. J Neuroinflammation 10:108-110. CrossRef Medline

Sheng M, Kim MJ (2002) Postsynaptic signaling and plasticity mechanisms. Science 298:776-780. CrossRef Medline

Staniland AA, Clark AK, Wodarski R, Sasso O, Maione F, D'Acquisto F, Malcangio M (2010) Reduced inflammatory and neuropathic pain and decreased spinal microglial response in fractalkine receptor (CX3CR1) knockout mice. J Neurochem 114:1143-1157. CrossRef Medline

Sun W, McConnell E, Pare JF, Xu Q, Chen M, Peng W, Lovatt D, Han X, Smith Y, Nedergaard M (2013) Glutamate-dependent neuroglial calcium signaling differs between young and adult brain. Science 339:197200. CrossRef Medline

Svensson CI, Yaksh TL (2002) The spinal phospholipase-cyclooxygenaseprostanoid cascade in nociceptive processing. Annu Rev Pharmacol Toxicol 42:553-583. CrossRef Medline

Svensson CI, Marsala M, Westerlund A, Calcutt NA, Campana WM, Freshwater JD, Catalano R, Feng Y, Protter AA, Scott B, Yaksh TL (2003) Activation of p38 mitogen-activated protein kinase in spinal microglia is a critical link in inflammation-induced spinal pain processing. J Neurochem 86:1534-1544. CrossRef Medline

Taylor AL, Bonventre JV, Uliasz TF, Hewett JA, Hewett SJ (2008) Cytosolic phospholipase A2 alpha inhibition prevents neuronal NMDA receptorstimulated arachidonic acid mobilization and prostaglandin production but not subsequent cell death. J Neurochem 106:1828-1840. CrossRef Medline

Williams JH, Errington ML, Lynch MA, Bliss TV (1989) Arachidonic acid induces a long-term activity-dependent enhancement of synaptic transmission in the hippocampus. Nature 341:739-742. CrossRef Medline

Xanthos DN, Sandkühler J (2014) Neurogenic neuroinflammation: inflammatory CNS reactions in response to neuronal activity. Nat Rev Neurosci 15:43-53. CrossRef Medline

Zhong Y, Zhou LJ, Ren WJ, Xin WJ, Li YY, Zhang T, Liu XG (2010) The direction of synaptic plasticity mediated by $\mathrm{C}$-fibers in spinal dorsal horn is decided by Src-family kinases in microglia: the role of tumor necrosis factor-alpha. Brain Behav Immun 24:874-880. CrossRef Medline

Zhuang ZY, Kawasaki Y, Tan PH, Wen YR, Huang J, Ji RR (2007) Role of the CX3CR1/p38 MAPK pathway in spinal microglia for the development of neuropathic pain following nerve injury-induced cleavage of fractalkine. Brain Behav Immun 21:642-651. CrossRef Medline 